\title{
ECONOMETRICA
}

\section{Rational Asset Pricing Bubbles}

Author(s): Manuel S. Santos and Michael Woodford

Source: Econometrica, Vol. 65, No. 1 (Jan., 1997), pp. 19-57

Published by: The Econometric Society

Stable URL: http://www.jstor.org/stable/2171812

Accessed: $25 / 11 / 2013$ 12:59

Your use of the JSTOR archive indicates your acceptance of the Terms \& Conditions of Use, available at http://www.jstor.org/page/info/about/policies/terms.jsp

JSTOR is a not-for-profit service that helps scholars, researchers, and students discover, use, and build upon a wide range of content in a trusted digital archive. We use information technology and tools to increase productivity and facilitate new forms of scholarship. For more information about JSTOR, please contact support@jstor.org. 


\title{
RATIONAL ASSET PRICING BUBBLES
}

\author{
By Manuel S. SANTOS AND Michael WoOdFord ${ }^{1}$
}

\begin{abstract}
This paper provides a fairly systematic study of general economic conditions under which rational asset pricing bubbles may arise in an intertemporal competitive equilibrium framework. Our main results are concerned with nonexistence of asset pricing bubbles in those economies. These results imply that the conditions under which bubbles are possible -including some well-known examples of monetary equilibria - are relatively fragile.
\end{abstract}

KEYwords: Asset pricing bubbles, rational expectations, sequentially incomplete markets, money.

THIS PAPER IS CONCERNED with the conditions under which asset prices in an intertemporal competitive equilibrium are equal to the present value of the streams of future dividends to which each asset represents a claim. According to a central result of the theory of finance, this is very generally true in the case of economies with trading at only a finite sequence of dates, as long as there are no restrictions upon transactions other than that associated with possible incompleteness of the set of securities that are traded. (The result is sometimes called "the fundamental theorem of asset pricing.") Here we consider the extent to which such a result continues to be valid in the case of trading over an infinite horizon.

It has often been observed in the econometric literature on "asset pricing bubbles" that it is possible, in principle, for the price of a perpetuity and the dividends on that security to satisfy at all times a present-value relation for one-period holding returns, while the security's price nonetheless does not equal the present value of the stream of dividends expected over the infinite future. In such a case, the price of the perpetuity is said to involve a bubble component. ${ }^{2}$ Joint stochastic processes for which this component is nonzero are sometimes argued to characterize existing assets; for a recent example, see Froot and Obstfeld (1991). But such an inference depends upon aspects of the stochastic

\footnotetext{
${ }^{1}$ This article is a drastic revision of an earlier, more extensive draft. We would like to thank Buz Brock, Douglas Gale, Takashi Kamihigashi, an editor, and two anonymous referees for helpful comments, and the Instituto de Matemática Pura e Aplicada (Rio de Janeiro) and the Bonn Workshop in Mathematical Economics for their hospitality while part of this work was completed. We would also like to acknowledge financial support from DGICYT (Spain) under Grant No. PS900014, from NSF (U.S.A.) under Grants Nos. SES-89-11264 and SES-92-10278, from Deutsche Forschungsgemeinschaft, Sonderforschungsbereich 303, and from Gottifred-Wilhelm-LeibnizFörderpreis.

${ }^{2}$ For expositions of this familiar idea, see, e.g., Blanchard and Fischer (1989, Ch. 5), or Broze and Szafarz (1991, Sec. 2.3.4).
} 
processes that are inherently difficult to determine with finite data samples. Hence, clarification of the conditions under which such phenomena are theoretically possible is likely to play an important role in judgements about whether they are observed.

It has been known since the work of Scheinkman $(1977,1988)$ and Brock $(1979,1982)$ that at least in certain simple kinds of infinite-horizon economies, involving trading by at most a finite number of infinitely lived households, asset pricing bubbles are not possible in an intertemporal equilibrium. The argument is, essentially, that the existence of a bubble would require asymptotic growth in the value of the asset in question, and hence asymptotic growth of the wealth of at least one of the households, at a rate inconsistent with optimization by that household. Here we seek to extend this result to a much more general class of intertemporal equilibrium models. In particular, we wish to consider the issue in a framework general enough to include such possibilities as the kind of economies treated by Scheinkman and Brock, while also including types of economies known to allow bubbles as an equilibrium phenomenon under at least certain circumstances, such as the overlapping generations model treated by Tirole (1985) or the type of monetary economy considered by Bewley (1980).

Our framework for analysis is an intertemporal general equilibrium model involving spot markets for goods and securities at each of a countably infinite sequence of dates. Thus we depart from the methods of analysis of much of the literature on intertemporal general equilibrium theory, which assumes that all dated and contingent future goods are traded for one another in a single market. This is because the phenomenon that we wish to consider is only a possibility if a security's exchange can always conceivably be due to its expected exchange value in another market in the future, rather than having solely to depend upon the value of the future goods to which it represents a claim. ${ }^{3} \mathrm{We}$ also allow for potentially incomplete securities markets, that is, for cases where there are not even sequentially complete markets in the sense introduced by Arrow. This complicates the definition of the "fundamental value" of an asset; it also allows for bubbles in additional types of cases. Likewise, we allow for incomplete participation of households in the entire sequence of spot markets, so that our framework can treat standard overlapping generations models. Finally, we allow for a reasonably general specification of borrowing constraints, to encompass in our analysis both the kinds of models with infinitely lived

\footnotetext{
${ }^{3}$ The meaning that we attach to the term "bubble" is thus different from the senses in which this term is used by Gilles and LeRoy $(1992,1993)$. For us, a "pricing bubble" exists when the price of an asset differs from the value (in a sense to be clarified in Section 2) of the stream of dividends to which it is a claim. Thus it is neither a property of the valuation operator for such dividend streams, nor a property of the dividend streams; and indeed, when pricing bubbles are possible in our framework, it is possible in equilibrium for two securities representing claims to identical dividend streams to have different market prices. (See Tirole (1985) and Example 4.1 below.) The relation that may exist between the conditions that exclude "bubbles" in the Gilles-LeRoy senses and those that exclude bubbles in our sense remains an open question.
} 
households previously considered by Scheinkman and Brock on the one hand, and those considered by Bewley on the other. ${ }^{4}$

Our intertemporal equilibrium framework is described in Section 1. In Section 2 , we then discuss the meaning of the "fundamental value" of a security, and hence what it means for there to exist a "pricing bubble." Here we reconstruct, in our framework, certain aspects of the Kreps (1981) theory of the extent to which arbitrary dividend streams can be priced, given price processes for certain traded securities, simply from consideration of the prices consistent with nonexistence of opportunities for pure arbitrage profits. The existence of an infinite horizon requires fundamental modification of that theory; for example, it is no longer true, simply because a market price exists for a security giving rise to exactly a dividend stream, that the dividend stream must be assigned that price.

These developments of arbitrage theory over an infinite horizon are the basic tools of our analysis in Section 3. In this section, we establish our main results regarding nonexistence of pricing bubbles in an equilibrium with the property that the economy's aggregate endowment has a finite value. These results are discussed further in Section 4, through the presentation of examples that illustrate the need for various of our assumptions. While several cases are analyzed in which equilibrium pricing bubbles are possible, our general results imply that these examples, including the well-known examples of monetary equilibria mentioned earlier, hold only under rather special circumstances. Section 5 concludes.

\section{THE MODEL}

We consider an infinite-horizon economy with homogeneous information and sequential trading. Trading occurs at each information set (or node) in the information structure $N$. Each information set in $N$ is dated with one of the discrete sequence of dates $t=0,1,2 \ldots$. We use the notation $s^{t}$ to denote one of the information sets that may be reached at date $t$. Each information set $s^{t}$ has a unique immediate predecessor, which we will denote $s^{t}-1$, that is dated $t-1$. There is a unique initial information set $s^{0}$, the only one dated 0 . Each node has a finite number of immediate successors. We use the notation $s^{T} \mid s^{t}$ to indicate that the node $s^{T}$ belongs to the subtree whose root is $s^{t}$, i.e., that either $s^{T}=s^{t}$ or $s^{t}$ is a predecessor of $s^{T}$.

At each node $s^{t} \in N$, there exist spot markets for $n\left(s^{t}\right)$ consumption goods and $k\left(s^{t}\right)$ securities, where both of these are finite numbers. The set of households which are able to trade in the markets at node $s^{t}$ is denoted by $H\left(s^{t}\right)$; this is a subset of the countable set of households $H$ that make up the economy. We allow for the possibility of incomplete participation at some nodes so that we can treat cases such as overlapping generations models. Let $N^{h}$ denote the

\footnotetext{
${ }^{4}$ Kocherlakota (1992) emphasizes the role of the different types of borrowing constraints in accounting for the difference between the possibilities of speculative bubbles in the two types of models. His analysis, however, is concerned with necessary conditions for the existence of asset pricing bubbles, and applies only to economies with no uncertainty.
} 
subset of $N$ consisting of nodes at which household $h$ can trade, for any household $h \in H ; s^{t} \in N^{h}$ if and only if $h \in H\left(s^{t}\right)$. Then a household is infinitely lived if for any date $T$, there exists some $s^{t} \in N^{h}$ with $t \geq T$; otherwise, the household is finitely lived.

We make the following assumptions about market participation. For each $h \in H$, let $\bar{N}^{h} \subset N^{h}$ denote the (possibly empty) subset of $N^{h}$ consisting of terminal nodes for $h$, i.e., nodes after which $h$ no longer trades. (To be precise, $s^{t} \in \bar{N}^{h}$ means that if $s^{T} \mid s^{t}$ for some $T>t$, then $s^{T} \notin N^{h}$.) We then assume:

(i) for each $h \in H$, if $s^{t} \in N^{h}, s^{t} \notin \bar{N}^{h}$, and $s^{t+1} \mid s^{t}$, then $s^{t+1} \in N^{h}$; and

(ii) for each $s^{t} \in N$, there exists at least one $h \in H$ for which $s^{t} \in N^{h} \backslash \bar{N}^{h}$.

Assumption (i) states that a household that trades at $s^{t}$ either trades at none of the successors of $s^{t}$ (if it is a terminal node for that household), or trades at all of the immediate successors of $s^{t}$ (if it is not a terminal node). This eliminates ambiguity about the type of securities that households can trade with one another at a given node. Assumption (ii) guarantees that the entire economy is connected.

The securities that are traded are defined by a current vector of prices, $q\left(s^{t}\right)$, and the returns they promise to deliver at future information sets. These returns are specified by an $n\left(s^{t}\right) \times k\left(s^{t}-1\right)$ matrix $d\left(s^{t}\right)$, and a $k\left(s^{t}\right) \times k\left(s^{t}-1\right)$ matrix $b\left(s^{t}\right)$, defined for each node $s^{t}$ with $t>0$. A household that chooses to hold a portfolio $z \in \mathscr{R}^{k\left(s^{t}-1\right)}$ at the end of trading at node $s^{t}-1$ then obtains a vector of goods dividends $d\left(s^{t}\right) z$ and a vector of securities $b\left(s^{t}\right) z$ if information set $s^{t}$ is reached. This allows us to treat general multi-period securities. Among other cases, we may consider trading in fiat money, a security $m$ such that

$$
\begin{array}{ll}
d_{i m}\left(s^{t}\right)=0 & \text { for all } i, \text { all } s^{t} \text { with } t>0, \\
b_{j m}\left(s^{t}\right)=0 & \text { for all } j \neq m, \text { all } s^{t} \text { with } t>0, \\
b_{m m}\left(s^{t}\right)=1 & \text { for all } s^{t} \text { with } t>0 .
\end{array}
$$

We may also consider bonds that promise future payments of money, if money itself is one of the traded securities.

We also assume that there is free disposal of every security that is purchased. In order for this assumption to make sense in general circumstances, we require that at each $s^{t} \in N$ with $t>0, d\left(s^{t}\right), b\left(s^{t}\right) \geq 0$. Thus the stream of dividends to which any security represents a claim is nonnegative in all goods at all information sets, and the future securities to which any security represents a claim are also a nonnegative vector (with, accordingly, a nonnegative market value).

Each household $h \in H\left(s^{0}\right)$ enters the spot markets at $s^{0}$ with an initial endowment of securities $\tilde{z}^{h}\left(s^{0}\right)$. The net supply of securities at each node $s^{t}, z\left(s^{t}\right)$, can then be defined recursively as

$$
\begin{aligned}
& z\left(s^{0}\right)=\sum_{h \in H\left(s^{0}\right)} z^{h}\left(s^{0}\right), \\
& z\left(s^{t}\right)=b\left(s^{t}\right) z\left(s^{t}-1\right) .
\end{aligned}
$$


In the case that $H\left(s^{0}\right)$ is an infinite set, we require that initial securities endowments be such that the sum in the first line is well-defined (and finite). There is then a well-defined and finite net supply of securities in all periods. We assume that $z\left(s^{0}\right) \geq 0$, though individual households may have negative initial endowments. This implies that $z\left(s^{t}\right) \geq 0$ at all nodes, so that all securities are in either zero or positive net supply.

We can now determine the stream of future dividends associated with any given security. For all $s^{r} \mid s^{t}$ with $r \geq t$, let the $k\left(s^{r}\right) \times k\left(s^{t}\right)$ matrix $e\left(s^{r} \mid s^{t}\right)$ be defined recursively as

$$
\begin{aligned}
& e\left(s^{t} \mid s^{t}\right)=I_{k\left(s^{t}\right)}, \\
& e\left(s^{r} \mid s^{t}\right)=b\left(s^{r}\right) e\left(s^{r}-1 \mid s^{t}\right), \quad \text { for all } s^{r} \mid s^{t}, r>t .
\end{aligned}
$$

Then for all $s^{r} \mid s^{t}$ with $r>t$, let the $n\left(s^{r}\right) \times k\left(s^{t}\right)$ matrix $x\left(s^{r} \mid s^{t}\right)$ be defined as

$$
x\left(s^{r} \mid s^{t}\right)=d\left(s^{r}\right) e\left(s^{r}-1 \mid s^{t}\right) .
$$

We may then say that the portfolio $z$ of securities held at the end of trading at node $s^{t}$ represents a claim to a stream of dividends, namely, the vector $x\left(s^{r} \mid s^{t}\right) z$ for goods at each node $s^{r} \mid s^{t}$ with $r>t$.

A security $j$ traded at $s^{t}$ is of finite maturity if there exists a date $T$ such that $e_{i j}\left(s^{r} \mid s^{t}\right)=0$ for all $i$, all $s^{r} \mid s^{t}$ with $r \geq T$. Otherwise, the security is of infinite maturity. Fiat money, defined above, is an example of a security of infinite maturity, even though $d_{i m}\left(s^{t}\right)=0$ for all $i$ and all $s^{t}$.

At each node $s^{t} \in N^{h}$, each household $h \in H\left(s^{t}\right)$ has an endowment of consumption goods $w^{h}\left(s^{t}\right) \in \mathscr{R}_{+}^{n\left(s^{t}\right)}$. We furthermore suppose that the economy has a well-defined (and finite) aggregate endowment

$$
w\left(s^{t}\right) \equiv \sum_{h \in H\left(s^{t}\right)} w^{h}\left(s^{t}\right) \geq 0
$$

at each node $s^{t}$. Considering the goods that are real dividends on securities in positive net supply, the economy's aggregate goods supply is then given by

$$
\tilde{w}\left(s^{t}\right) \equiv w\left(s^{t}\right)+d\left(s^{t}\right) z\left(s^{t}-1\right) \geq 0 .
$$

(In this definition, the final term is zero if $t=0$.)

Each household is assumed to have preferences represented by an ordering $\succsim^{h}$, defined on its consumption set

$$
X^{h}=\prod_{s^{t} \in N^{h}} \mathscr{R}_{+}^{n\left(s^{t}\right)}
$$

That is, it is defined for all consumption plans involving nonnegative consumption goods at each node $s^{t} \in N^{h}$. For simplicity, the consumption set extends over all goods in the information set where an agent can trade. This hypothesis can be weakened to allow for more general or alternative settings. It is nonetheless essential for our results that consumption sets be bounded below so 
as to place an upper bound on the total amount of goods that can be sold at a given information set.

We make the following monotonicity assumption regarding preferences:

(A.1) For each $h \in H$, the relation $\succsim^{h}$ is nondecreasing on $X^{h}$, and strictly increasing in the consumption of some good traded at each node $s^{t} \in N^{h}$.

Our results are strengthened if we postulate a further joint assumption on preferences and endowments, implying a sufficient degree of impatience. For any vector $c^{h} \in X^{h}$ and any node $s^{t} \in N^{h}$, we can write $c^{h}=$ $\left(c_{-}^{h}\left(s^{t}\right), c^{h}\left(s^{t}\right), c_{+}^{h}\left(s^{t}\right)\right)$, where $c_{-}^{h}$ denotes the coordinates of $c^{h}$ indicating consumption at nodes other than the subtree of nodes $s^{T} \in N^{h}$ such that $s^{T} \mid s^{t}$, and $c_{+}^{h}\left(s^{t}\right)$ denotes those indicating consumption at nodes $s^{T} \in N^{h}$ such that $s^{T} \mid s^{t}$ and $T>t$. Then for some results we also require:

(A.2) For each $h \in H$, there exists $0 \leq \gamma^{h}<1$ such that for any $s^{t} \in N^{h}$,

$$
\left(c_{-}^{h}\left(s^{t}\right), c^{h}\left(s^{t}\right)+\tilde{w}\left(s^{t}\right), \gamma c_{+}^{h}\left(s^{t}\right)\right) \succ{ }^{h} c^{h}
$$

for all consumption plans satisfying $c^{h}\left(s^{T}\right) \leq \tilde{w}\left(s^{T}\right)$ at each $s^{T} \in N^{h}$, and all $\gamma \geq \gamma^{h}$.

Here $\succ^{h}$ denotes strict preference. Note that the consumption plans to which (A.2) refers include all those that are associated with feasible allocations of resources. Also note that $\gamma^{h}$ may be different for each $h \in H$, and that we do not require that the collection $\left\{\gamma^{h}\right\}$ be bounded away from 1. This kind of uniform impatience is also assumed by Levine and Zame (1994) and Magill and Quinzii (1994). In the case of finitely lived households, (A.2) must hold if preferences are described by any continuous utility function, and is thus innocuous in that case. In the case of infinitely lived households, the assumption is less trivial, though it is satisfied in the case of any continuous, stationary, recursive utility function that discounts the future (see Santos and Woodford (1993, Sec. 6) for a precise statement), and thus in many familiar models. Example 4.5 below considers a (product continuous) preference ordering for an infinitely lived household that does not satisfy (A.2).

Household $h$ chooses, at each node $s^{t} \in N^{h}$, an $n\left(s^{t}\right)$-vector of assumption goods $c^{h}\left(s^{t}\right)$, and a $k\left(s^{t}\right)$-vector of securities $z^{h}\left(s^{t}\right)$ to hold at the end of trading, subject to the budget constraints:

$$
p\left(s^{t}\right)^{\prime} c^{h}\left(s^{t}\right)+q\left(s^{t}\right)^{\prime} z^{h}\left(s^{t}\right) \leq p\left(s^{t}\right)^{\prime} w^{h}\left(s^{t}\right)+R\left(s^{t}\right)^{\prime} z^{h}\left(s^{t}-1\right),
$$

(1.1b) $\quad c^{h}\left(s^{t}\right) \geq 0$,

(1.1c) $\quad q\left(s^{t}\right)^{\prime} z^{h}\left(s^{t}\right) \geq-B^{h}\left(s^{t}\right)$.

Here, $p\left(s^{t}\right)$ denotes the $n\left(s^{t}\right)$-vector of goods prices in the spot market at node $s^{t}, q\left(s^{t}\right)$ denotes the $k\left(s^{t}\right)$-vector of securities prices, and

$$
R\left(s^{t}\right)^{\prime} \equiv p\left(s^{t}\right)^{\prime} d\left(s^{t}\right)+q\left(s^{t}\right)^{\prime} b\left(s^{t}\right)
$$

denotes the $k\left(s^{t}-1\right)$-vector of one-period returns if node $s^{t}$ is reached. 
Condition (1.1a) is just the standard Arrow-Radner budget constraint for an economy with sequential trading. If $t>0$, but household $h$ does not trade at $s^{t}-1,(1.1 \mathrm{a})$ has the same form, but with $z^{h}\left(s^{t}-1\right)=0$. If $t=0,(1.1 \mathrm{a})$ takes the special form

$$
p\left(s^{0}\right)^{\prime} c^{h}\left(s^{0}\right)+q\left(s^{0}\right)^{\prime} z^{h}\left(s^{0}\right) \leq p\left(s^{0}\right)^{\prime} w^{h}\left(s^{0}\right)+q\left(s^{0}\right)^{\prime} \tilde{z}^{h}\left(s^{0}\right)
$$

Condition (1.1b) restates again the lower bound on the consumption set. Condition (1.1c) specifies a limit on the extent to which household $h$ can finance consumption at node $s^{t}$ by borrowing. The quantity $B^{h}\left(s^{t}\right)$ indicates a household specific borrowing limit at node $s^{t}$, assumed to be nonnegative. We may suppose in general that the borrowing limit depends upon equilibrium prices; examples of such dependence are discussed in Section 4. But because we are not concerned here with issues related to the existence or uniqueness of equilibrium, or how an equilibrium changes when some parameters of the economy are perturbed, we do not need to model explicitly the dependence of $B^{h}$ upon $(p, q){ }^{5}$ In the characterization of equilibrium that we give here, we simply suppose that household $h$ takes the sequence of borrowing limits $\left\{B^{h}\left(s^{t}\right)\right\}$ as given, just as it takes the prices as given, and our only general assumption regarding the nature of the borrowing limits is that $B^{h}\left(s^{t}\right) \geq 0$ for each household $h$ at each node $s^{t}$ and that $B^{h}\left(s^{t}\right)=0$ for $s^{t} \in \bar{N}^{h}$.

If the matrix $V\left(s^{t}\right)$, which has one row corresponding to $R\left(s^{t+1}\right)^{\prime}$ for each of the nodes $s^{t+1} \mid s^{t}$, has a rank equal to the number of rows (the number of immediate successor nodes), we say that there exist complete markets at node $s^{t}$. Otherwise, securities markets are incomplete. Complete markets obviously requires that the number of securities traded at $s^{t}$ be at least as large as the number of immediate successor nodes. In general, complete markets is a property of a particular equilibrium, rather than that of the specification of the economy.

Let an economy with sequential trading be specified by an information structure $N$, a set of households $H$, the participation sets $\left\{N^{h}\right\}$, the securities processes $\left\{b\left(s^{t}\right), d\left(s^{t}\right)\right\}$, the initial securities endowments $\left\{\tilde{z}^{h}\right\}$, the endowment processes $\left\{w^{h}\left(s^{t}\right)\right\}$, the preferences $t^{h}$ over consumption sets $X^{h}$, and the functions defining the borrowing limits $\left\{B^{h}\left(s^{t}\right)\right\}$, given price processes $\left\{p\left(s^{t}\right), q\left(s^{t}\right)\right\}$. Then the processes $\left\{p\left(s^{t}\right), q\left(s^{t}\right), \bar{c}^{h}\left(s^{t}\right), \bar{z}^{h}\left(s^{t}\right)\right\}$ describe an Arrow-Radner equilibrium if:

(i) for each $h \in H$, the processes $\left\{\bar{c}^{h}\left(s^{t}\right), \bar{z}^{h}\left(s^{t}\right)\right\}$ are optimal under the preferences $z^{h}$, subject to budget constraints (1.1) being satisfied at each

\footnotetext{
${ }^{5}$ See Hernández and Santos (1994), Levine and Zame (1994), and Magill and Quinzii (1994) for treatments of existence of equilibrium in infinite-horizon economies with incomplete markets and borrowing limits. The existence of an equilibrium generally requires further assumptions on preferences, endowments and borrowing limits. Such assumptions are not needed for our results on the pricing of securities in a given equilibrium.
} 
$s^{t} \in N^{h}$, given prices $\left\{p\left(s^{t}\right), q\left(s^{t}\right)\right\}$ and the borrowing limits $\left\{B^{h}\left(s^{t}\right)\right\}$ resulting from them;

(ii) for each $s^{t} \in N$,

(1.2a) $p\left(s^{t}\right) \geq 0$

(1.2b) $\quad q\left(s^{t}\right) \geq 0$;

(iii) for each $s^{t} \in N$,

$$
\sum_{h \in H\left(s^{t}\right)} \bar{c}^{h}\left(s^{t}\right) \leq \tilde{w}\left(s^{t}\right),
$$

$$
\sum_{h \in H\left(s^{t}\right)} \bar{z}^{h}\left(s^{t}\right) \leq z\left(s^{t}\right) ; \quad \text { and }
$$

(iv) for each $s^{t} \in N$,

$$
\begin{aligned}
& p\left(s^{t}\right)^{\prime}\left[\sum_{h \in H\left(s^{t}\right)} \bar{c}^{h}\left(s^{t}\right)-\tilde{w}\left(s^{t}\right)\right]=0, \\
& q\left(s^{t}\right)^{\prime}\left[\sum_{h \in H\left(s^{t}\right)} \bar{z}^{h}\left(s^{t}\right)-z\left(s^{t}\right)\right]=0 .
\end{aligned}
$$

Here, $(1.2 \mathrm{a}-\mathrm{b})$ are equilibrium requirements as a result of free disposal. Note that the sum in (1.3a) and (1.4a) is necessarily well-defined (as consumption must be nonnegative for each household), so that we can say unambiguously whether the conditions are satisfied. The same is not true of the sum in (1.3b) and (1.4b). Nonetheless, we take it to be part of the definition of equilibrium that if $H\left(s^{t}\right)$ is an infinite set, then the portfolios chosen are such that the aggregate portfolio demand is well defined.

In the sequel we shall only consider equilibria in which every $s^{t}$ in $N$ has the property that $R\left(s^{t+1} \mid s^{t}\right) \neq 0$ for some $s^{t+1} \mid s^{t}$; that is, in which there exists some way of carrying wealth into some successor. This avoids discussion of a number of technicalities (taken up in Santos and Woodford (1993)). In particular, it eliminates the possibility of a particular kind of pricing bubble that can in any event occur only under quite pathological circumstances. In the absence of other comment, we will always understand "equilibrium" to refer to one of this kind.

\section{PRICING BY ARBITRAGE AND THE VALUE OF A DIVIDEND STREAM}

This section provides a complete characterization of the possible valuations of an arbitrary income stream of wealth in our infinite horizon framework under conditions of no arbitrage. Then attention is focused on the relation that must exist between the price of a security and the value of the stream of dividends to which it represents a claim, and on certain assumptions that guarantee the existence of a finite-valued aggregate wealth. As a step toward this end, we first 
derive certain basic properties concerning prices and one-period returns of different securities if there are to be no pure arbitrage profits available.

Given the price processes $(p, q)$, we say that no arbitrage opportunities exist at node $s^{t}$ if there is no $z \in \mathscr{R}^{k\left(s^{t}\right)}$ satisfying the conditions

$$
\begin{aligned}
& R\left(s^{t+1}\right)^{\prime} z \geq 0 \quad \text { for all } s^{t+1} \mid s^{t}, \\
& q\left(s^{t}\right)^{\prime} z \leq 0,
\end{aligned}
$$

with at least one strict inequality.

As is well known from the theory of finite-horizon Arrow-Radner equilibria, this is necessarily true at any node $s^{t} \in N$ in any equilibrium if there are no borrowing limits at that node. We now observe that the presence of borrowing limits (1.1c) does not change this result, at least in the case of equilibria in which $R\left(s^{t+1} \mid s^{t}\right)>0$ for some $s^{t+1} \mid s^{t}$; for in such case one likewise shows that a given household could obtain an arbitrary amount of wealth in at least one state without committing further expenditure in the remaining nodes.

As is familiar from the finite-horizon theory, the nonexistence of arbitrage opportunities at node $s^{t}$ implies the existence of a set of state prices $a\left(s^{t}\right)>0$ and $\left\{a\left(s^{t+1}\right)\right\}$ with $a\left(s^{t+1}\right)>0$ for all $s^{t+1} \mid s^{t}$, such that

$$
a\left(s^{t}\right) q\left(s^{t}\right)^{\prime}=\sum_{s^{t+1} \mid s^{t}} a\left(s^{t+1}\right) R\left(s^{t+1}\right)^{\prime} .
$$

This well-known result is a consequence of the Minkowski-Farkas Lemma (see, e.g., Duffie (1988, p. 71)). It should be obvious that only the ratios $a\left(s^{t+1}\right) / a\left(s^{t}\right)$ are restricted by (2.1); hence the existence result for each node $s^{t}$ individually allows us to define some state-price process $\left\{a\left(s^{t}\right)\right\}$ for the entire information structure such that (2.1) holds. We use $A\left(s^{t}\right)$ to denote the set of such processes for the subtree with root $s^{t}{ }^{6}$ In the case that there are complete markets at $s^{t}$, (2.1) uniquely determines the ratios $a\left(s^{t+1}\right) / a\left(s^{t}\right)$ for each $s^{t+1} \mid s^{t}$, while if there are incomplete markets, there are not a sufficient number of linearly independent conditions in (2.1) to uniquely determine them.

Such a set of state prices provides an obvious way of evaluating a future stream of consumption goods. For any nonnegative stream of resources $\left\{x\left(s^{t}\right)\right\}$, specifying an $n\left(s^{t}\right)$-vector of consumption goods $x\left(s^{t}\right) \geq 0$ at each node $s^{t} \in N$, any positive goods price process $\left\{p\left(s^{t}\right)\right\}$, and any positive state-price process $a \in A\left(s^{t}\right)$, one can define the present value at $s^{t}$ of the subsequent resource stream, with respect to this particular state-price process, as

$$
v_{x}\left(s^{t} ; p, a\right) \equiv \frac{1}{a\left(s^{t}\right)} \sum_{T=t+1}^{\infty} \sum_{s^{T} \mid s^{t}} a\left(s^{T}\right) p\left(s^{T}\right)^{\prime} x\left(s^{T}\right) .
$$

\footnotetext{
${ }^{6}$ There is an extensive related work on the existence of "martingale measures" in infinite dimensional spaces under conditions of "no arbitrage." Schachermayer (1994) reviews some of this work and provides an extension of these results to an infinite-horizon framework.
} 
This is clearly a meaningful expression, though the sum may diverge (in which case we say that $v_{x}=+\infty$ ). Note, however, that the present value need not be uniquely defined, except in the case of complete markets.

Similarly, for any state-price process $a \in A\left(s^{t}\right)$,

$$
f\left(s^{t} ; p, a\right)^{\prime} \equiv \frac{1}{a\left(s^{t}\right)} \sum_{T=t+1}^{\infty} \sum_{s^{T} \mid s^{t}} a\left(s^{T}\right) p\left(s^{T}\right)^{\prime} x\left(s^{T} \mid s^{t}\right)
$$

defines a $k\left(s^{t}\right)$-vector of fundamental values for the securities traded at node $s^{t}$. Observe that the fundamental value is defined only with reference to a particular state-price process. Some properties of the fundamental value are, however, true regardless of the state prices chosen.

Proposition 2.1: At each $s^{t} \in N$, the vector of fundamental values defined in (2.2) is well-defined for any $a \in A\left(s^{t}\right)$, and satisfies

$$
0 \leq f\left(s^{t}\right) \leq q\left(s^{t}\right) \text {. }
$$

Proof: Equation (2.1) may be written

$$
\begin{aligned}
a\left(s^{t}\right) q\left(s^{t}\right)^{\prime}= & \sum_{s^{t+1} \mid s^{t}} a\left(s^{t+1}\right) p\left(s^{t+1}\right)^{\prime} x\left(s^{t+1} \mid s^{t}\right) \\
& +\sum_{s^{t+1} \mid s^{t}} a\left(s^{t+1}\right) q\left(s^{t+1}\right)^{\prime} e\left(s^{t+1} \mid s^{t}\right) .
\end{aligned}
$$

Repeated application of this equation yields

$$
\begin{aligned}
a\left(s^{t}\right) q\left(s^{t}\right)^{\prime}= & \sum_{T=t+1}^{\hat{T}} \sum_{s^{T} \mid s^{t}} a\left(s^{T}\right) p\left(s^{T}\right)^{\prime} x\left(s^{T} \mid s^{t}\right) \\
& +\sum_{s^{\hat{T}} \mid s^{t}} a\left(s^{\hat{T}}\right) q\left(s^{\hat{T}}\right)^{\prime} e\left(s^{\hat{T}} \mid s^{t}\right)
\end{aligned}
$$

for any horizon $\hat{T}>t$. But $e\left(s^{\hat{T}} \mid s^{t}\right) \geq 0$, which together with (1.2b) implies

$$
a\left(s^{t}\right) q\left(s^{t}\right)^{\prime} \geq \sum_{T=t+1}^{\hat{T}} \sum_{s^{T} \mid s^{t}} a\left(s^{T}\right) p\left(s^{T}\right)^{\prime} x\left(s^{T} \mid s^{t}\right) .
$$

Since $x\left(s^{T} \mid s^{t}\right) \geq 0$ for all $s^{T}$, the right-hand side of (2.3) is a nondecreasing series in $\hat{T}$. Because of (2.3), the series is bounded above, and so must converge to a limit no greater than the left-hand side.

Q.E.D.

Note that the assumption of free disposal is used to guarantee (2.3). In the absence of free disposal, neither the bound nor the convergence need obtain, even if a security is a claim to a positive flow of goods. (See Brock (1990) and Santos and Woodford (1993, Example 5.4).) 
We can correspondingly define the vector of asset pricing bubbles as

$$
\sigma\left(s^{t}\right) \equiv q\left(s^{t}\right)-f\left(s^{t}\right)
$$

for any $a \in A\left(s^{t}\right)$ for securities traded at $s^{t}$. It follows from the proposition that this vector is well-defined and necessarily satisfies the bounds

$$
0 \leq \sigma\left(s^{t}\right) \leq q\left(s^{t}\right) .
$$

We thus obtain in a quite general setting the often-remarked "impossibility of negative bubbles" (e.g., Diba and Grossman (1988), Blanchard and Fischer (1989, Ch. 5)). Substituting this definition and (2.2) into (2.1), we get

$$
a\left(s^{t}\right) \sigma\left(s^{t}\right)^{\prime}=\sum_{s^{t+1} \mid s^{t}} a\left(s^{t+1}\right) \sigma\left(s^{t+1}\right)^{\prime} e\left(s^{t+1} \mid s^{t}\right) .
$$

Hence, we also find in this context that any vector of asset pricing bubbles must satisfy a (generalized) martingale property. In particular, (2.4) implies that if there exists a nonzero pricing bubble on any security at date $t$, there must exist a bubble as well on some securities at date $T$, with positive probability, at every date $T>t$. Furthermore, if there exists a bubble on any security in positive net supply, then there must have existed a bubble as well on some security in positive net supply at every predecessor of the node $s^{t}$; there is thus a clear sense in which a bubble can "never start," in a rational expectations equilibrium with free disposal.

One case in which (2.2) results in an unambiguous definition of the fundamental value, even with incomplete markets, is that of a security of finite maturity. In such case, the fundamental value of a given security $j$, defined as in (2.2), is the same for all state-price processes $a \in A\left(s^{t}\right)$, and the uniquely defined fundamental value is $f_{j}\left(s^{t}\right)=q_{j}\left(s^{t}\right)$, so that there is no pricing bubble for this security. (The proof of this assertion simply repeats that of Proposition 2.1 , taking $\hat{T}$ to be a date far enough in the future so that $e_{j}\left(s^{\hat{T}} \mid s^{t}\right)=0$ for all $s^{\hat{T}} \mid s^{t}$ and $x^{j}\left(s^{T} \mid s^{t}\right)=0$ for all $s^{T} \mid s^{t}$ with $T>\hat{T}$.)

In the case of securities of infinite maturity in an economy with incomplete markets, the fundamental value need not be the same for all state-price processes consistent with the available securities returns. But even in this case, we can at any rate define the range of variation in the fundamental value, given the restrictions upon possible state prices implied by observed securities prices. Let $\left\{x\left(s^{t}\right)\right\}$ again be a nonnegative stream of resources. Then at any node $s^{t}$ we may define

$$
\underline{\pi}_{x}\left(s^{t}\right) \equiv \sup -q\left(s^{t}\right)^{\prime} z\left(s^{t}\right)
$$

where the supremum is over all plans $\left\{z\left(s^{r}\right)\right\}$ for the nodes $s^{r} \mid s^{t}, r \geq t$, such that:

(i) the plan $\left\{z\left(s^{r}\right)\right\}$ satisfies

$$
p\left(s^{r}\right)^{\prime} x\left(s^{r}\right)+R\left(s^{r}\right)^{\prime} z\left(s^{r}-1\right) \geq q\left(s^{r}\right)^{\prime} z\left(s^{r}\right)
$$

for all $s^{r} \mid s^{t}, r>t$; and

(ii) there exists a date $T$ such that $q\left(s^{r}\right)^{\prime} z\left(s^{r}\right) \geq 0$ for all $s^{r} \mid s^{t}$ with $r \geq T$. 
In other words, $\underline{\pi}_{x}\left(s^{t}\right)$ represents the least upper bound for the amount that can be borrowed at node $s^{t}$ by a household whose endowment is $\left\{x\left(s^{r}\right)\right\}$ at all subsequent nodes, if the borrowing limits (1.1c) are ignored, but the household must hold nonnegative wealth at all nodes after some finite date. This is a way of assigning a lower bound to the present value, at node $s^{t}$, of a claim to dividends $\left\{x\left(s^{r}\right)\right\}$ at all subsequent nodes.

Similarly, at node $s^{t}$ we may define

$$
\bar{\pi}_{x}\left(s^{t}\right) \equiv \inf q\left(s^{t}\right)^{\prime} z\left(s^{t}\right)
$$

where the infimum is over all plans $\left\{z\left(s^{r}\right)\right\}$ for the nodes $s^{r} \mid s^{t}, r \geq t$, such that

$$
\begin{aligned}
& R\left(s^{r}\right)^{\prime} z\left(s^{r}-1\right) \geq p\left(s^{r}\right)^{\prime} x\left(s^{r}\right)+q\left(s^{r}\right)^{\prime} z\left(s^{r}\right), \\
& q\left(s^{r}\right)^{\prime} z\left(s^{r}\right) \geq 0,
\end{aligned}
$$

for all $s^{r} \mid s^{t}, r>t$. Essentially, $\bar{\pi}_{x}\left(s^{t}\right)$ represents a greatest lower bound for the amount of wealth needed at node $s^{t}$ in order to be able to purchase a consumption stream equal to the process $\left\{x\left(s^{r}\right)\right\}$ at all subsequent nodes, if the household must hold nonnegative wealth at all nodes from $s^{t}$ onward.

These bounds represent a lower and an upper bound, respectively, for the present value of the nonnegative stream of resources $\left\{x\left(s^{r}\right)\right\} .{ }^{7}$ This is shown by the following basic result.

PROPOSITION 2.2: Let $\left\{x\left(s^{r}\right)\right\}$ be a process satisfying $x\left(s^{r}\right) \geq 0$ at each $s^{r} \mid s^{t}$, and let $\bar{\pi}_{x}\left(s^{t}\right)$ and $\underline{\pi}_{x}\left(s^{t}\right)$ be defined as above. Then

$$
\begin{aligned}
& \bar{\pi}_{x}\left(s^{t}\right)=\sup _{a \in A\left(s^{t}\right)} v_{x}\left(s^{t} ; p, a\right), \\
& \underline{\pi}_{x}\left(s^{t}\right) \leq \inf _{a \in A\left(s^{t}\right)} v_{x}\left(s^{t} ; p, a\right) .
\end{aligned}
$$

Suppose furthermore that $\underline{\pi}_{x}\left(s^{r}\right)<+\infty$ for all $s^{r} \mid s^{t}$. (For this it suffices, because of (2.7b), that there exists a state-price process $a \in A\left(s^{t}\right)$ such that $v_{x}\left(s^{t} ; p, a\right)<+\infty$.) Then

$$
\underline{\pi}_{x}\left(s^{t}\right)=\inf _{a \in A\left(s^{t}\right)} v_{x}\left(s^{t} ; p, a\right)
$$

The proof is given in the Appendix. The possible failure of $(2.7 \mathrm{c})$ in the absence of additional hypotheses is illustrated by the following example.

EXAMPLE 2.1: Let $N$ consist of $s^{0}$ and two date $t$ nodes, $\xi_{t}$ and $\eta_{t}$, for each $t \geq 1$. Node $s^{0}$ has two immediate successors $\xi_{1}$ and $\eta_{1}$; every other node has only one immediate successor (the successor of $\xi_{t}$ being $\xi_{t+1}$, and of $\eta_{t}$ being

${ }^{7}$ Our definitions of these bounds, as well as the characterization in Proposition 2.2, are in the spirit of those in Kreps (1981), although we cannot directly apply Kreps' results, due to certain differences in our set-up, such as our restriction of the consumption set to the nonnegative orthant. 
$\left.\eta_{t+1}\right)$. There is a single consumption good at each node, which we choose as numeraire $\left(p\left(s^{t}\right)=1\right.$ for each $\left.s^{t}\right)$. One security is traded at each node, and $q\left(s^{t}\right)=1$ for each $s^{t}, R\left(s^{t}\right)=1$ for each $s^{t}$ with $t \geq 1$. Clearly there are no arbitrage opportunities at any node. Consider the value of a resource stream given by $x\left(\xi_{t}\right)=0, x\left(\eta_{t}\right)=1 / 2$, for all $t \geq 1$.

In this example, the set of state-price processes $a \in A\left(s^{0}\right)$ is the set of processes of the form

$$
\begin{aligned}
& a\left(\xi_{t}\right) / a\left(s^{0}\right)=\alpha \quad \text { for all } t \geq 1, \\
& a\left(\eta_{t}\right) / a\left(s^{0}\right)=1-\alpha \quad \text { for all } t \geq 1,
\end{aligned}
$$

for arbitrary $0<\alpha<1$. In the case of any such process, $v_{x}\left(\eta_{t} ; p, a\right)=+\infty$ for all $t \geq 1$, and so $v_{x}\left(s^{0} ; p, a\right)=+\infty$ as well. Thus

$$
\inf _{a \in A\left(s^{0}\right)} v_{x}\left(s^{0} ; p, a\right)=+\infty .
$$

On the other hand, it is easily seen that $\pi_{x}\left(s^{0}\right)=0$. Any portfolio trading plan with $z\left(s^{0}\right)<0$, that is feasible apart from the borrowing limits, would have to involve $z\left(\xi_{t}\right)<0$ for all $t \geq 1$, so that there is no finite date at which wealth becomes nonnegative. Therefore, $(2.7 \mathrm{~b})$ is satisfied in this example, but (2.7c) fails at the initial node $s^{0}$. This does not contradict Proposition 2.2, because in this case $\underline{\pi}_{x}\left(\eta_{t}\right)=+\infty$ for all $t \geq 1$.

Thus for any state-price process, and any security $j$ traded at $s^{t}$, the fundamental value, defined as in (2.2), must lie between the bounds $\underline{\pi}_{x}\left(s^{t}\right)$ and $\bar{\pi}_{x^{j}}\left(s^{t}\right)$, where $x^{j}$ refers to the dividend process $\left\{x^{j}\left(s^{r} \mid s^{t}\right)\right\}$. These are furthermore the tightest bounds with this property. For it follows from Propositions 2.1 and 2.2 that the bounds $\underline{\pi}_{x}\left(s^{r}\right)$ and $\bar{\pi}_{x^{\prime}}\left(s^{r}\right)$ are finite, and satisfy

$$
\underline{\pi}_{x^{\prime}}\left(s^{r}\right) \leq \bar{\pi}_{x^{\prime}}\left(s^{r}\right) \leq q\left(s^{r}\right)^{\prime} e_{j}\left(s^{r} \mid s^{t}\right)<+\infty
$$

at all $s^{r} \mid s^{t}$. Hence (2.7c) applies in the case of a dividend stream $\left\{x^{j}\left(s^{r} \mid s^{t}\right)\right\}$.

In the event that $\underline{\pi}_{x^{j}}\left(s^{t}\right)=\bar{\pi}_{x^{\prime}}\left(s^{t}\right)$, the fundamental value is uniquely defined. This is necessarily true in the case of complete markets, but can also occur with incomplete markets. On the other hand, with incomplete markets it is possible that the two bounds do not coincide. In such a case, the fundamental value may be different for different values of the state-price processes. Hence the existence or not of a pricing bubble may be ambiguous. There unambiguously exists no bubble if $\underline{\pi}_{x}\left(s^{t}\right)=\bar{\pi}_{x^{\prime}}\left(s^{t}\right)=q_{j}\left(s^{t}\right)$; and conditions under which this must be true in equilibrium, even with incomplete markets, are given in Theorem 3.3. Likewise, there unambiguously exists a pricing bubble if $\bar{\pi}_{x^{j}}\left(s^{t}\right)<q_{j}\left(s^{t}\right)$. But these two cases are not the only possibilities, in the case of incomplete markets. If $\underline{\pi}_{x}\left(s^{t}\right)<\bar{\pi}_{x^{j}}\left(s^{t}\right)=q_{j}\left(s^{t}\right)$, the existence or not of a bubble depends upon which 
of the state-price processes $a \in A\left(s^{t}\right)$ one chooses. ${ }^{8}$ Conditions are given in Theorem 3.1 for the latter equality to hold, which do not preclude the inequality holding as well; and Example 4.5 illustrates this possibility.

Before turning to a further analysis of the bubble component of securities prices, it is useful to define a particular type of borrowing limit that will be used subsequently. One may say that borrowing is limited only by one's ability to repay out of one's future endowment if

$$
B^{h}\left(s^{t}\right)=\underline{\pi}_{w^{h}}\left(s^{t}\right)
$$

for each $s^{t} \in N^{h} \backslash \bar{N}^{h}$. These are the tightest borrowing limits with the property that any plan satisfying (1.1a)-(1.1b) at all nodes, and such that there exists a date $T$ after which wealth is always nonnegative, is permissible. It can be shown that, even in the case of incomplete markets, such borrowing limits never bind (effectively) at any finite date. Thus they represent a constraint only upon the asymptotic behavior of a household's debt, and indeed it can be shown to be equivalent to the kind of "transversality condition" used to define the budget constraint of infinitely lived households by authors such as Scheinkman (1977, 1988) and Brock $(1979,1982)$. In the case of finitely lived households, these borrowing limits are equivalent to imposing no borrowing limits at all nonterminal nodes. ${ }^{9}$ An important consequence of this specification is the following.

PROPOSITION 2.3: Suppose that household $h$ has borrowing limits of the form (2.8). Then the existence of an optimal plan $\left(\bar{c}^{h}, \bar{z}^{h}\right)$ for the price processes $(p, q)$ implies that $\underline{\pi}_{w^{h}}\left(s^{t}\right)<+\infty$ at each $s^{t} \in N^{h}$, so that there is a finite borrowing limit at each node. Furthermore, the borrowing limit can equivalently be expressed as

$$
B^{h}\left(s^{t}\right)=\inf _{a \in A\left(s^{t}\right)} v_{w^{h}}\left(s^{t} ; p, a\right)<+\infty .
$$

Thus borrowing limits of this kind represent an obvious generalization, to the case of incomplete markets, of the familiar "present-value budget constraint" for the case of complete markets. One reason that this result, proved in the Appendix, is of interest is that the present value of a household's endowment must be finite, at least for some possible definitions of the present value, in any equilibrium; this will prove useful in Section 3.

The above bounds on fundamental values also allow us to extend to the case of incomplete markets the notion of an equilibrium in which the aggregate endowment of the economy has a finite value, a case known to be of special

\footnotetext{
${ }^{8}$ To be precise, Proposition 2.2 implies only that if $\bar{\pi}_{x^{j}}\left(s^{t}\right)=q_{j}\left(s^{t}\right)$, there exists a state-price process $a \in A\left(s^{t}\right)$ in terms of which the bubble component of the price is arbitrarily small; it need not be possible to make it zero, as $A\left(s^{t}\right)$ is not closed. But Theorem 3.1 gives sufficient conditions not simply for $\bar{\pi}_{x^{\prime}}\left(s^{t}\right)$ to equal $q_{j}\left(s^{t}\right)$, but for there to exist a state-price process in terms of which $f_{j}\left(s^{t} ; p, a\right)=q_{j}\left(s^{t}\right)$, as shown by explicit construction of the state prices.

${ }^{9}$ See Levine and Zame (1994), Magill and Quinzii (1994), and Santos and Woodford (1993, Sec. 2) for further discussion of the properties of borrowing limits of this kind.
} 
interest in the theory of infinite-horizon economies with complete markets (see, e.g., Wilson (1981)). We will say that the aggregate endowment is bounded by a portfolio trading plan if $\bar{\pi}_{w}\left(s^{t}\right)<+\infty$ for all $s^{t} \in N$. In the case of complete markets at every node, this condition is equivalent to a finite value for the aggregate endowment, if it is priced using the unique state-price process; this is a simple consequence of Proposition 2.2. In the case of incomplete markets, it implies a finite value regardless of the state-price process used, and indeed a bounded value for all positive state-price processes. We have stated the definition in terms of the aggregate endowment $\left\{w\left(s^{t}\right)\right\}$, which is not the aggregate supply of consumption goods in general. The aggregate supply of goods is instead given by $\left\{\tilde{w}\left(s^{t}\right)\right\}$, where $\tilde{w}\left(s^{t}\right)=w\left(s^{t}\right)+d\left(s^{t}\right) z\left(s^{t}-1\right)$ for all $s^{t}$ with $t>0$, and $\tilde{w}\left(s^{0}\right)=w\left(s^{0}\right)$. However, it readily follows from (2.3) and (2.7a) that $\bar{\pi}_{w}\left(s^{t}\right)<+\infty$ if and only if $\bar{\pi}_{\tilde{w}}\left(s^{t}\right)<+\infty$.

The definition of this condition involves the spot price process $(p, q)$. We can, however, state conditions relating only to the specification of an economy that imply that in any equilibrium the condition must hold. The following is a simple example.

LEMMA 2.4: Suppose that there exists a portfolio $\hat{z} \in \mathscr{R}_{+}^{k\left(s^{0}\right)}$ such that

$$
x\left(s^{t} \mid s^{0}\right) \hat{z} \geq w\left(s^{t}\right)
$$

for all $s^{t} \in N$ with $t>0$. Then in any equilibrium the aggregate endowment is bounded by a portfolio trading plan.

Note that condition (2.9) does not say anything about the initial net supply of securities $z\left(s^{0}\right)$-it is only necessary that $\hat{z}$ represent a portfolio that can be purchased in the spot markets at $s^{0}$. The proof is simple. In any equilibrium, $p\left(s^{t}\right) \geq 0, q\left(s^{t}\right) \geq 0, x\left(s^{t} \mid s^{0}\right) \hat{z} \geq 0$, and $e\left(s^{t} \mid s^{0}\right) \hat{z} \geq 0$ for all $s^{t}$. Then consider the portfolio trading plan defined by $\hat{z}\left(s^{t}\right)=e\left(s^{t} \mid s^{0}\right) \hat{z}$ for all $s^{t}$. For any node $s^{t}$, this together with the plan $x=w$ satisfies conditions (2.6) for all $s^{T} \mid s^{t}$. It then follows immediately from the definition of $\bar{\pi}$ that

$$
\bar{\pi}_{w}\left(s^{t}\right) \leq q\left(s^{t}\right)^{\prime} e\left(s^{t} \mid s^{0}\right) \hat{z}<+\infty .
$$

The case of an aggregate endowment that is bounded by a portfolio trading plan seems to be of considerable interest on empirical grounds. Abel et al. (1989) show that for several advanced industrial economies, the difference between gross returns to capital and gross investment, considered as a fraction of gross national product, appears to be consistently bounded above zero. In terms of our notation, this means that observations are consistent with the supposition that for some $k>0$,

$$
D\left(s^{t}\right) \geq k p\left(s^{t}\right)^{\prime} \tilde{w}\left(s^{t}\right)
$$

for all $s^{t}$, where $D\left(s^{t}\right)$ denotes the difference between the returns to capital and investment at node $s^{t}$. Now suppose that claims to the aggregate capital stock 
are among the set of traded securities. ${ }^{10}$ At any node $s^{t}$, let $\hat{z}\left(s^{t}\right) \geq 0$ denote the portfolio consisting of a claim to the aggregate capital stock. Then consider the consumption/portfolio trading plan that consists of holding at each node $k^{-1} \hat{z}\left(s^{t}\right)$, and consuming at each node the aggregate goods supply $\tilde{w}\left(s^{t}\right)$. Given (2.10), this plan satisfies conditions (2.6) for all $s^{t}$ with $t>0$, and involves a nonnegative portfolio at each node. It then follows that $\bar{\pi}_{\tilde{w}}\left(s^{t}\right) \leq k^{-1} q\left(s^{t}\right)^{\prime} \hat{z}\left(s^{t}\right)$ $<+\infty$ at each $s^{t} \in N$, so that $\bar{\pi}_{w}\left(s^{t}\right)<+\infty$ as well. Hence the empirical support for the Abel et al. criterion suggests that the case of an aggregate endowment bounded by a portfolio trading plan is of considerable practical importance. ${ }^{11}$

As a simple illustration of why the condition is important, we offer the following result.

PROPOSITION 2.5: Let preferences satisfy ( $A$.1) and consider an equilibrium $\left\{p, q, \bar{c}^{h}, \bar{z}^{h}\right\}$. For any node $s^{t} \in N$, let $\left\{\sigma\left(s^{r}\right)\right\}$ be the vector of bubble components for the securities traded at each node $s^{r} \mid s^{t}$, when fundamental values are defined using state prices $a \in A\left(s^{t}\right)$, and suppose that $v_{w}\left(s^{t} ; p, a\right)<+\infty$ (and hence $\left.v_{\tilde{w}}\left(s^{t} ; p, a\right)<+\infty\right)$ when these state prices are used. Suppose furthermore that there exists a nonzero bubble on some security in positive net supply traded at $s^{t}$, so that $\sigma\left(s^{t}\right)^{\prime} z\left(s^{t}\right)>0$. Then for any $K<+\infty$, there exist a date $T$ and a node $s^{T} \mid s^{t}$ at which

$$
\sigma\left(s^{T}\right)^{\prime} z\left(s^{T}\right)>K p\left(s^{T}\right)^{\prime} \tilde{w}\left(s^{T}\right) .
$$

That is, there is a positive probability that the total size of the bubble component on all securities in existence becomes an arbitrarily large multiple of the value of the aggregate supply of goods in the economy.

The proof of this proposition simply follows from the basic observation that by the martingale property of pricing bubbles (equality (2.4)) we must have that $a\left(s^{t}\right) \sigma\left(s^{t}\right)^{\prime} z\left(s^{t}\right)=\sum_{s^{T} \mid s^{t}} a\left(s^{T}\right) \sigma\left(s^{T}\right)^{\prime} z\left(s^{T}\right)$ remains constant for all $T>t$, whereas

\footnotetext{
${ }^{10}$ We can represent an economy with capital and production in terms of our framework by taking the production plan as given, rather than something to be determined. We also replace household's labor endowments at each node with a share of output at that node, of value equal to their wages in the production economy, and replace the firm sector with a perpetuity whose "dividends" at each node equal the aggregate output not used for investment purposes, net of the shares of output imputed to households in replacement of their wages. If there are nonproduced inputs other than labor, they are dealt with similarly: the part of households' endowments of these materials that are used in production are replaced by a share of output of value equal to the factor payments in the production economy. Then $D\left(s^{t}\right)$ is the value of the dividends at node $s^{t}$ on this perpetuity. The necessary conditions for an equilibrium of the endowment economy so constructed are among the necessary conditions for an equilibrium of the original production economy. In fact, our results extend rather directly to production economies, but we do not take this up here.

${ }^{11}$ Note, however, that the Abel et al. criterion could hold, without the aggregate endowment being bounded by a portfolio trading plan, if not all capital goods are traded, and the incompleteness of markets is such that no portfolio can replicate the returns on the aggregate capital stock. See Blanchard and Weil (1992) for an example.
} 
$\sum_{s^{T} \mid s^{t}} a\left(s^{T}\right) p\left(s^{T}\right) \tilde{w}\left(s^{T}\right)$ converges to zero, as $T$ goes to $+\infty$, since $v_{\tilde{w}}\left(s^{t} ; p, a\right)<$ $+\infty$.

\section{MAIN RESULTS}

As one might expect from Proposition 2.5, a finite value for the aggregate endowment severely restricts the class of cases in which pricing bubbles on securities in positive net supply are possible at all. This is because some household or households must accumulate vast wealth in such an equilibrium as the value of their consumption goes to zero. It is not obvious, however, that such behavior is inconsistent with optimization in our intertemporal framework with incomplete markets, borrowing limits, and incomplete participation of agents in the entire sequence of markets. Indeed, Example 4.5 illustrates that for some state-price processes pricing bubbles may arise in an equilibrium of a simple economy with a representative consumer. Our most general result is the following.

THEOREM 3.1: Let preferences satisfy (A.1), and consider an equilibrium $\left\{p, q, \bar{c}^{h}, \bar{z}^{h}\right\}$. For any $s^{t} \in N$, suppose that $\bar{\pi}_{w}\left(s^{t}\right)<+\infty$. Then there exists a state-price process $a \in A\left(s^{t}\right)$ such that $q_{j}\left(s^{T}\right)=f_{j}\left(s^{T} ; a, p\right)$ for all $s^{T} \mid s^{t}$, for each security $j$ traded at $s^{T}$ that is either (a) of finite maturity or (b) in positive net supply (i.e., for which $z_{j}\left(s^{T}\right)>0$ ).

Thus, under the hypotheses of the theorem, there are, in a certain sense, no speculative bubbles, except possibly on securities that are both of infinite maturity and in zero net supply. On the other hand, this theorem does not assert that there is an unambiguous fundamental value for any security in positive net supply; it implies that $q_{j}\left(s^{T}\right)=\bar{\pi}_{x^{\prime}}\left(s^{T}\right)$ for any such security, but it does not exclude the possibility that $q_{j}\left(s^{T}\right)>\underline{\pi}_{x}\left(s^{T}\right)$, so that there also exist state-price processes $a \in A\left(s^{t}\right)$ in terms of which the market price of the security exceeds its fundamental value.

A case in which Theorem 3.1 implies an unequivocal result is the following.

Corollary 3.2: Suppose that one of the securities traded at each node $s^{t} \in N$ is fiat money (defined in Section 1), and consider an equilibrium satisfying the hypotheses of Theorem 3.1 at all nodes. Then fiat money has no value in this equilibrium; i.e., $q_{m}\left(s^{t}\right)=0$ for each $s^{t} \in N$.

This follows directly from the theorem, for the fundamental value of fiat money is zero at all nodes, regardless of the state prices used to compute present values.

Theorem 3.1 can be strengthened if one assumes a sufficient degree of impatience.

THEOREM 3.3: Let preferences satisfy ( $A$.1) and ( $A .2)$, and consider an equilibrium $\left\{p, q, \bar{c}^{h}, \bar{z}^{h}\right\}$. For any node $s^{t} \in N$, assume that there exists a state-price 
process $a \in A\left(s^{t}\right)$ such that $v_{w}\left(s^{t} ; p, a\right)<+\infty$ when these state prices are used. Then $q_{j}\left(s^{T}\right)=f_{j}\left(s^{T} ; a, p\right)$ for all $s^{T} \mid s^{t}$, for each security $j$ traded at $s^{T}$ that is either (a) of finite maturity or (b) in positive net supply (i.e., for which $z_{j}\left(s^{T}\right)>0$ ).

This result is an improvement of Theorem 3.1 in two respects. First of all, if $\bar{\pi}_{w}\left(s^{t}\right)<+\infty$, then given the stronger assumption on preferences it follows that there unambiguously exist no bubbles regardless of the state prices chosen, since for all such state-price processes, $q_{j}\left(s^{T}\right)=f_{j}\left(s^{T}\right)$. And second, it extends the class of cases for which bubbles do not exist. It is now sufficient that $v_{w}\left(s^{t} ; p, a\right)$ be finite for some state-price process, rather than it having to be true for all sets of state prices consistent with the values of traded securities.

These theorems apply to a broad class of economies in which the equilibrium value of the aggregate goods supply is bounded. We now give two simple sets of restrictions upon economic primitives that guarantee applicability of the theorems in any equilibrium. Both results apply regardless of the possible incompleteness of markets.

COROLlaRY 3.4: Let preferences satisfy (A.1) and suppose that there exists a portfolio $\hat{z}$ satisfying (2.9) for all $s^{t}$ with $t>0$. Then for any equilibrium $\left\{p, q, \bar{c}^{h}, \bar{z}^{h}\right\}$ there exists a state price process $a \in A\left(s^{0}\right)$ such that the conclusions of Theorem 3.1 hold. If in addition preferences satisfy (A.2), then these conclusions hold for every state-price process $a \in A\left(s^{0}\right)$.

This result follows directly from Theorems 3.1 and 3.3, making use of Lemma 2.4. It should be pointed out that if preferences do not satisfy (A.2), a pricing bubble may exist in terms of some state prices; this is illustrated by Example 4.5 below. This corollary implies that well-known examples of models that allow for valued fiat money, such as the overlapping generations model of Samuelson (1958) or the consumption-smoothing model of Bewley (1980), no longer admit monetary equilibria if additional markets are opened for securities of the kind assumed in the corollary. ${ }^{12}$

COROLlaRY 3.5: Let preferences satisfy ( $A .1)$ and ( $A .2)$, and suppose that there exist an infinitely lived household $h \in H$ and $\varepsilon>0$ such that $(i) w^{h}\left(s^{t}\right) \geq \varepsilon w\left(s^{t}\right)$ for each $s^{t} \in N$, and (ii) the borrowing limit $B^{h}\left(s^{t}\right)$ is specified by (2.8). Then for any equilibrium $\left\{p, q, \bar{c}^{h}, \bar{z}^{h}\right\}$, there exists a state-price process $a \in A\left(s^{0}\right)$ such that the conclusions of Theorem 3.3 hold.

This result follows from Theorem 3.3, making use of Proposition 2.3. By the proposition, there must exist some state-price process $a \in A\left(s^{0}\right)$ in terms of which $v_{w^{h}}\left(s^{0} ; p, a\right)<+\infty$. By assumption, $w^{h} \geq \varepsilon w$. Hence, $v_{w}\left(s^{0} ; p, a\right)<+\infty$ as

\footnotetext{
${ }^{12}$ On the possibility of monetary equilibria when such markets are closed, see Examples 4.1, 4.2, and 4.4 below.
} 
well. Consequently, $a \in A\left(s^{0}\right)$ is a state-price process for which the theorem applies.

Note that (A.2) is not needed for such a result to hold in the case of complete markets. For if the state prices $a \in A\left(s^{0}\right)$ are unique (up to normalization of an arbitrary $a\left(s^{0}\right)>0$ ), Propositions 2.2 and 2.3 then imply that $\bar{\pi}_{w^{h}}\left(s^{0}\right)<+\infty$, so that Theorem 3.1 applies. Nor is it necessary, in the case of complete markets, that there be a single household whose endowment satisfies hypothesis (i) of the corollary. It suffices that there be a finite collection $\tilde{H}$ of households, each with borrowing limits given by (2.8) and for each of whom $N^{h}$ has a finite number of root nodes (nodes with no predecessors), such that the aggregate endowment of the households in $\tilde{H}$ satisfies hypothesis (i). For then Proposition 2.3 implies that for each $h \in \tilde{H}$ and for each root node $s^{r}$ of $N^{h}, v_{w^{h}}\left(s^{r} ; p, a\right)<+\infty$ in terms of the unique state-price process $a$. Summing over all root nodes of $N^{h}$ for each $h \in \tilde{H}$, and summing over all $h \in \tilde{H}$, yields a finite number for the aggregate endowment of the group, and hence for the aggregate endowment of the economy. Then Theorem 3.1 applies. ${ }^{13}$

Corollary 3.5 implies that monetary equilibria necessarily cease to exist in an overlapping generations model, if there exists a family whose successive generations are linked by altruistic bequests, and so behave like a single infinitely lived household (as argued by Barro (1974)), if that family controls at least a fraction $\varepsilon>0$ of total resources at all dates, and the family is able to borrow against its future endowment income. The corollary similarly implies that monetary equilibria are not possible in the model of Bewley (1980), if some household type has endowment bounded away from zero in all states, and that household's borrowing limit is of the form (2.8). This shows the extent to which Bewley's monetary equilibria depend upon restrictions on borrowing limits. ${ }^{14}$

The proofs of Theorems 3.1 and 3.3 both build upon a strategy that has previously been used in the context of economies with complete markets (e.g., Brock $(1979,1982)$, Scheinkman $(1977,1988)$, and Wilson (1981)). The essential idea is the following. As shown in Section 2, if there is a bubble on a security in positive net supply, then the net present value of aggregate wealth at date $T$ does not approach zero as $T$ is made unboundedly large. On the other hand, if there is a finite upper bound on the value of aggregate consumption (given by the finite bound on the value of the aggregate endowment), the present value of consumption from date $T$ onward must tend to zero as $T$ is made large. Thus if there is a bubble, for a date $T$ sufficiently far in the future, the present value of some household's wealth exceeds that of its subsequent consumption; but this can be shown to be inconsistent with optimization by the household even with incomplete markets and borrowing limits. Of course, in the case of incomplete markets an added difficulty appears, as present values are not unambiguously defined.

\footnotetext{
${ }^{13}$ This last result generalizes one of Wilson (1981).

${ }^{14}$ Example 4.4 provides a counterexample to Corollary 3.5 , and depends upon every household type having a zero endowment in some states.
} 
Crucial preliminary results thus establish bounds upon the amount of wealth that households can hold, consistent with optimization, determined by the value of planned future consumption. In proving Theorem 3.1, we rely upon the following.

LEMMA 3.6: Let preferences satisfy ( $A .1)$, and consider an equilibrium $\left\{p, q, \bar{c}^{h}, \bar{z}^{h}\right\}$. Then for any $s^{t} \in N$ and any $h \in H\left(s^{t}\right)$,

$$
q\left(s^{t}\right)^{\prime} \bar{z}^{h}\left(s^{t}\right) \leq \bar{\pi}_{\left(\bar{c}^{h}-w^{h}\right)^{+}}\left(s^{t}\right)
$$

where $\left(\bar{c}^{h}-w^{h}\right)^{+}\left(s^{T}\right) \equiv \max \left(\bar{c}^{h}\left(s^{T}\right)-w^{h}\left(s^{T}\right), 0\right)$ for all $s^{T} \mid s^{t}$ with $T>t$.

The proof is given in the Appendix. This result does not immediately give a bound for aggregate wealth in terms of the present value of aggregate consumption, if there are incomplete markets, for the upper bound $\bar{\pi}_{x}$ defined in Section 2 is not a linear operator. Nonetheless, we may establish the existence of such a bound, if present values are computed using the right state prices. The following result is used to prove Theorem 3.1. Again, the proof is given in the Appendix.

Lemma 3.7: Let the hypotheses of Theorem 3.1 be satisfied. Then for any $s^{t} \in N$ and any $0<\delta<1$, there exist a state-price process $\bar{a} \in A\left(s^{t}\right)$ and $a$ date $T>t$ such that

$$
\sum_{r=t+1}^{T} \sum_{s^{r} \mid s^{t}} \bar{a}\left(s^{r}\right) p\left(s^{r}\right)^{\prime}\left[\sum_{h \in H\left(s^{r}\right)} \bar{c}^{h}\left(s^{r}\right)\right] \geq \delta \bar{a}\left(s^{t}\right) q\left(s^{t}\right)^{\prime} z\left(s^{t}\right)
$$

In proving Theorem 3.3, we rely upon the following stronger version of Lemma 3.6, that is possible under the stronger hypothesis on preferences.

LEMMA 3.8: Let preferences satisfy (A.1) and (A.2) for $h \in H$. For given prices $(p, q)$, let $\left(\bar{c}^{h}, \bar{z}^{h}\right)$ be an optimal plan for $h$, where $\bar{c}^{h}\left(s^{t}\right) \leq \tilde{w}\left(s^{t}\right)$ for each $s^{t} \in N^{h}$. Then for any $s^{t} \in N$, and any state-price process $a \in A\left(s^{t}\right)$ for which $v_{w}\left(s^{t} ; p, a\right)<$ $+\infty$, one must have

$$
\sum_{r=t+1}^{\infty} \sum_{\substack{s^{r} \mid s^{t} \\ s^{r} \in N^{h}}} a\left(s^{r}\right) p\left(s^{r}\right)^{\prime} \bar{c}^{h}\left(s^{r}\right) \geq a\left(s^{t}\right) v_{w^{h}}\left(s^{t} ; p, a\right)+a\left(s^{t}\right) q\left(s^{t}\right)^{\prime} \bar{z}^{h}\left(s^{t}\right)
$$

where the last term is zero if $s^{t} \notin N^{h}$.

This too is proved in the Appendix, which also contains the proofs of Theorems 3.1 and 3.3. Observe that in the case of complete markets inequality (3.3) is a simple consequence of (A.1). Example 4.5 illustrates, however, that unless further assumptions are imposed on preferences, inequality (3.3) will not hold for every feasible state-price process $a \in A\left(s^{t}\right)$. Also, note that the bound 
(3.3) can be summed over households, to obtain an upper bound upon aggregate wealth in terms of the present value of aggregate consumption, and that this bound holds for any state prices in terms of which the aggregate endowment has a finite value. This accounts for the stronger results obtained in Theorem 3.3.

Finally, observe that the stronger assumption (A.2) is not needed in order for the conclusion of Corollary 3.5 to hold, in the case of a representative household. In this simple case, Lemma 3.6 suffices to provide a bound on the value of aggregate wealth, since aggregate wealth is just the wealth of the representative household.

\section{EXAMPLES OF RATIONAL ASSET PRICING BUBBLES}

The nonexistence results for pricing bubbles in the previous section depend upon a number of assumptions. In this section, we demonstrate the importance of these assumptions by presenting a number of examples, in which rational asset pricing bubbles do exist, when one or another of the assumptions are violated.

Our first example shows that a pricing bubble is possible if no household is endowed with a positive fraction of the aggregate endowment, even when all other hypotheses of Corollary 3.5 are satisfied. This is also a simple example of an equilibrium with valued fiat money.

EXAMPLE 4.1: Here we recall the overlapping generations model of fiat money of Samuelson (1958) and Gale (1973). ${ }^{15}$ There is no uncertainty, so that the information structure is a sequence of dates $t=0,1,2 \ldots$. There is a single consumption good at each date, which we will take to be the numeraire for that date's spot markets. There is also a single security traded at each date, fiat money, defined by $d(t)=0, b(t)=1$, for all $t \geq 1$. Because fiat money has a positive exchange value in every period in the equilibrium described below, there are complete markets.

The economy consists of a countably infinite sequence of households $h=$ $0,1,2, \ldots$, and $N^{0}=\{0\}, N^{h}=\{h-1, h\}$ for each $h \geq 1$. Household 0 seeks to maximize its consumption at date 0 , while each household $h \geq 1$ seeks to maximize $U\left(c^{h}(h-1), c^{h}(h)\right)$. Here $U(\cdot, \cdot)$ is a strictly concave $C^{1}$ function, strictly increasing in both arguments, defined on $\mathscr{R}_{+}^{2}$. The endowment of household 0 is $w_{2}>0$ at date 0 , while the endowment of each household $h \geq 1$ is $w_{1}>0$ at date $h-1$ and $w_{2}>0$ at date $h$. Household 0 has an initial endowment of one unit of fiat money (the initial net supply), while each household $h \geq 1$ has none. Finally, the borrowing limits for each household are of the form (2.8), which is to say, at each date $t, B^{t}(t)=0, B^{t+1}(t)=w_{2} q(t) / q(t$ +1 ), given equilibrium prices such that $q(t)>0$ for all $t$. Note that such an economy satisfies all hypotheses of Corollary 3.5 except for (i).

\footnotetext{
${ }^{15}$ The significance of this model as an example of a rational asset pricing bubble is stressed by Tirole (1985).
} 
Let us assume in addition that the partial derivatives, $U_{1}\left(0, w_{1}+w_{2}\right)>$ $U_{2}\left(0, w_{1}+w_{2}\right), U_{1}\left(w_{1}, w_{2}\right)<U_{2}\left(w_{1}, w_{2}\right){ }^{16}$ Then there exists a rational expectations equilibrium in which $q(t)=q^{*}$ for each $t \geq 0$, where $q^{*}>0$ is the unique quantity such that

$$
U_{1}\left(w_{1}-q^{*}, w_{2}+q^{*}\right)=U_{2}\left(w_{1}-q^{*}, w_{2}+q^{*}\right) .
$$

The equilibrium consumption allocation is $\bar{c}^{h}(h-1)=w_{1}-q^{*}$ for each $h \geq 1$, $\bar{c}^{h}(h)=w_{2}+q^{*}$ for each $h \geq 0$, and the equilibrium portfolio allocation is $\bar{z}^{h}(h-1)=1, \bar{z}^{h}(h)=0$ for each $h \geq 1$. Note that fiat money has a positive value despite the fact that its fundamental value is uniquely defined and equal to zero.

Now suppose instead that two types of fiat money are traded at each date, defined by $d(t)=0, b(t)=I_{2}$, for each $t \geq 1$; and let household 0 have an initial endowment of one unit of each type of money. In this case, one possible equilibrium has $q_{1}(t)=q^{*}, q_{2}(t)=0$ for each $t \geq 0$, with the same consumption allocation as above. This shows that two securities with identical dividend streams may nonetheless have different prices. More generally, there exists an equilibrium for every pair of nonnegative numbers $q_{1}(t)=q_{1}$ and $q_{2}(t)=q_{2}$ for each $t \geq 0$, such that $q_{1}+q_{2}=q^{*}$, and with the same consumption allocation as above. (This is an example of the indeterminacy of equilibrium exchange rates discussed by Kareken and Wallace (1981).) This indeterminacy of the relative size of the "bubble components" of the prices of the two assets is an example of something that would be missed in using a formalism like that of Gilles and LeRoy (1993), that attributes the "bubble component" to the presence of a "payoff at infinity" in the security specification.

It is often asserted that "short horizons" for traders make rational bubbles possible, that would be eliminated if traders were concerned about returns that could be realized farther in the future ${ }^{17}$ Overlapping generations models do allow the existence of equilibria with bubbles under certain circumstances where they would be excluded in the case of an infinitely lived household, or even in the case of a finite number of households. (Recall the discussion after Corollary 3.5.) But the features of the overlapping generations structure that are crucial in such examples are that different households have very different endowment patterns and that the economy is not sufficiently productive (i.e., the aggregate allocation is not bounded by a portfolio trading plan) and not the fact that households can trade, or care about consumption, in only a finite number of periods.

Our next example shows that a pricing bubble is possible if borrowing limits are not of the form (2.8), even when all other hypotheses of Corollary 3.5 are

\footnotetext{
${ }^{16}$ These assumptions ensure that we have what Gale (1973) calls the "Samuelson case."

${ }^{17}$ See, e.g., the remarks of Stiglitz (1990). The contrast between the results of Tirole (1982) for an economy with infinitely lived traders and those of Tirole (1985) for an economy with overlapping generations of two-period lived households is sometimes interpreted in this way.
} 
satisfied. In this example, the lower bound $\underline{\pi}_{w}\left(s^{t}\right)=+\infty$, and in fact there exists valued fiat money, and this is possible because for each household the borrowing limits effectively bind infinitely often.

EXAMPLE 4.2: Here we recall a monetary model of Bewley (1980), discussed in detail in Sargent (1987, Ch. 6). This is a deterministic model with a single consumption good at each date, and fiat money is the only security traded at each date. The economy consists of two households, $h=1,2$, each of which trades at all dates $\left(N^{h}=N\right)$, and each of which seeks to maximize

$$
U^{h}\left(c^{h}\right)=\sum_{t=0}^{\infty} \beta^{t} u\left(c^{h}(t)\right)
$$

where $0<\beta<1$ and $u(\cdot)$ is a bounded, strictly increasing, strictly concave $C^{1}$ function, defined on $\mathscr{R}_{+}$. The endowment of household 1 is $w_{1}>0$ at all even-numbered dates and $w_{2}>0$ at odd-numbered dates, while the endowment of household 2 is $w_{2}$ at even-numbered dates and $w_{1}$ at odd-numbered ones. Household 2 has an initial endowment of one unit of fiat money (the initial net supply), while household 1 has none. Finally, the borrowing limits for each household are given by $B^{h}(t)=0$ for all $t \geq 0$.

Let us assume in addition that $u^{\prime}(0)>\beta u^{\prime}\left(w_{1}+w_{2}\right), u^{\prime}\left(w_{1}\right)<\beta u^{\prime}\left(w_{2}\right)$. Then there exists an equilibrium in which $q(t)=q^{*}$ for each $t \geq 0$, where $q^{*}>0$ is the unique quantity such that

$$
u^{\prime}\left(w_{1}-q^{*}\right)=\beta u^{\prime}\left(w_{2}+q^{*}\right) .
$$

The equilibrium consumption allocation is $\bar{c}^{h}(t)=w_{1}-q^{*}$ when $h=1$ and $t$ is even, or $h=2$ and $t$ is odd, and $\bar{c}^{h}(t)=w_{2}+q^{*}$ when $h=1$ and $t$ is odd, or $h=2$ and $t$ is even. The equilibrium portfolio allocation is $\bar{z}^{h}(t)=1$ when $h=1$ and $t$ is even, or $h=2$ and $t$ is odd, and $\bar{z}^{h}(t)=0$ when $h=1$ and $t$ is odd, or $h=2$ and $t$ is even. Again, fiat money has a positive value despite the fact that its fundamental value is zero.

Note that the economy satisfies all the assumptions of Corollary 3.5 except for (ii). In this case the borrowing limits bind for household 1 at every odd date, and for household 2 at every even date, and so both households are unable to borrow against the value of their future wealth. Indeed, in this equilibrium,

$$
\sum_{t=0}^{\infty} a(t) w^{h}(t)=+\infty
$$

for each household, and as a result the proof of Theorem 3.3 fails since $\underline{\pi}_{w}=+\infty$. This would not be possible if borrowing limits are of the standard form (2.8). (But see Example 4.4 below.)

Even when the conditions of Theorem 3.1 (or its corollaries) are satisfied, speculative bubbles are not excluded on securities of infinite maturity in zero 
net supply. The following example illustrates this possibility for an economy satisfying the hypotheses of Corollary 3.4 .

EXAMPLE 4.3: Again there is no uncertainty and a single consumption good at each date. There is a single security traded at each date, a perpetuity defined by $d(t)=d>0, b(t)=1$, for all $t \geq 0$. The economy consists of two households, $h=1,2$, with the same preferences and market participation as in Example 4.2. Endowments are given by $w^{h}(t)=w>0$ for $h=1,2$, and for each $t \geq 0$. Household 1 has an initial endowment of 1 unit of the bond, while household 2 has an initial endowment of -1 units. Thus the bond is in zero net supply; we may regard it as a liability of household 2 issued at some previous date, and held by household 1 at the beginning of period 0 . We assume that $w>d$, so that household 2 can pay the stream of dividends promised. The borrowing limits for each household are of the form (2.8), or equivalently (since there are complete markets), they are unambiguously defined by the present value of future wealth.

The following process describes an equilibrium for this economy:

$$
\begin{aligned}
& q(t)=\frac{\beta}{1-\beta} d+K \beta^{-t}, \\
& \bar{c}^{1}(t)=w+\beta d+(1-\beta) K, \\
& \bar{c}^{2}(t)=w-\beta d-(1-\beta) K, \\
& \bar{z}^{1}(t)=\frac{\left(\beta^{2} d / 1-\beta\right)+K \beta}{(\beta d / 1-\beta)+K \beta^{-t},} \\
& \bar{z}^{2}(t)=-\bar{z}^{1}(t) .
\end{aligned}
$$

Each expression holds for each $t \geq 0$, and $K$ is a constant in the interval $0 \leq K \leq(w-\beta d) /(1-\beta)$. (The lower bound is necessary in order to ensure that $q(t) \geq 0$ for all $t$; the upper bound is necessary in order to ensure that $\bar{c}^{2}(t) \geq 0$ for all $t$.) In the case of any such equilibrium, the unique state-price process is given by $a(t)=\beta^{t}$, as a result of which the uniquely defined fundamental value of the bond equals $(\beta /(1-\beta)) d$. Hence there unambiguously exists a pricing bubble in the case of any $K>0$.

We could introduce trading in a one-period bond each period, that is in zero net supply, without changing any aspect of the above equilibrium. If the one-period bond pays one unit of the consumption good a period later $\left(d^{2}(t)=1\right.$, $b^{2}(t)=0$ for all $t \geq 1$ ), its equilibrium price is $q^{2}(t)=\beta$ for all $t \geq 0$. Yet even with a second bond, the existence of a speculative bubble on the perpetuity does not imply the existence of an arbitrage opportunity. This is true even though each household trades at the entire infinite sequence of dates. It is not possible, for example, to sell short $\Delta$ units of the perpetuity, consume $K \Delta$, and invest $(\beta /(1-\beta)) d \Delta$ in the one-period bond, paying the dividends upon the shorted perpetuity in all subsequent periods out of the funds invested in the one-period bond (that are rolled over each period). The problem with such a plan is that it 
reduces the market value of the household's portfolio, $q(t)^{\prime} z(t)$, by an amount $K \Delta \beta^{-t}$ at each date $t$. This must violate the borrowing limit (2.8) for large enough $t$.

It is also worth remarking that if we allow modifications in the net supply of securities after date 0 (e.g., due to government issuance or retirement of securities), then existence of a speculative bubble under circumstances like those of this example requires only that the security be in asymptotically zero net supply. Thus, for example, a positive value for fiat money is possible, with a positive money supply at all dates, if the quantity of money in the hands of the private sector contracts to zero asymptotically. ${ }^{18}$

Our examples thus far have all involved complete markets. Incomplete markets do, however, make possible some qualitatively distinct phenomena. The following example shows that even with a finite number of agents and borrowing limits of the form (2.8), a speculative bubble is possible in the case of incomplete markets. The example thus illustrates the necessity of condition (i) in Corollary 3.5.

EXAMPLE 4.4: We present here a variant of a monetary economy analyzed by Kehoe, Levine, and Woodford (1992). At each date $t$, there is realized a random state $s_{t} \in\{\xi, \eta\}$. This follows a Markov process with

$$
\operatorname{Prob}\left(s_{t+1}=\xi \mid s_{t}=\eta\right)=\operatorname{Prob}\left(s_{t+1}=\eta \mid s_{t}=\xi\right)=\pi
$$

where $0<\pi<1$, given an initial condition $s_{0} \in\{\xi, \eta\}$. A node $s^{t} \in N$ can then be identified with a sequence $\left\{s_{0}, s_{1}, \ldots, s_{t}\right\} \in\{\xi, \eta\}^{t+1}$. There is a single consumption good at each node, and a single security is traded, fiat money (again in fixed net supply of one unit at all dates).

The economy consists of two households, $h=1,2$, each of which has preferences of the form

$$
\sum_{t=0}^{\infty} \sum_{s^{t}} \pi\left(s^{t}\right) \beta\left(s^{t}\right) u\left(c\left(s^{t}\right)\right)
$$

where $\pi\left(s^{t}\right)$ is the unconditional probability of node $s^{t}$, and $\beta\left(s^{t}\right)=\beta^{t}$ is the discount factor, assumed to be time stationary and the same for both households, with $0<\beta<1$. The (non-state-contingent) single period utility function $u(c)$ is likewise the same for both households. The function $u: \mathscr{R}_{+} \rightarrow \mathscr{R}$ is a strictly increasing, strictly concave, bounded $C^{1}$ function. The endowment of household 1 is 0 if the current state $s_{t}=\xi$, and $w>0$ if the current state $s_{t}=\eta$; the endowment of household 2 is $w>0$ if $s_{t}=\xi$ and 0 if $s_{t}=\eta$. Thus the aggregate endowment is always $w>0$. One household is initially endowed with

\footnotetext{
${ }^{18}$ For instance, see the "hyperdeflationary" equilibria in Woodford (1994). That paper considers an economy with a cash-in-advance constraint, but "hyperdeflationary" equilibria exist in which the constraint never binds, and corresponding monetary equilibria exist for a model with no such constraints.
} 
one unit of money, and the other with zero units; which household is which does not matter. Finally, both households have borrowing limits of the form (2.8). Because there is always a positive probability of receiving zero endowment in each of the next $T$ periods, for arbitrarily large $T$, it is obvious that $\underline{\pi}_{w} h\left(s^{t}\right)=0$ for $h=1,2$, and each $s^{t} \in N$, as long as fiat money has positive value for all $s^{t} \in N$. This is the kind of equilibrium that we consider. Hence borrowing is never possible $\left(B^{h}\left(s^{t}\right)=0\right.$ for $h=1,2$ and each $\left.s^{t} \in N\right)$, though these borrowing limits are of the form (2.8).

We suppose furthermore that

$$
\frac{\beta^{2} \pi(1-\pi)}{(1-\beta)+\beta \pi(1-\beta \pi)} \leq \frac{u^{\prime}(w)}{u^{\prime}(0)}<\frac{\beta \pi}{1-\beta+\beta \pi} .
$$

This condition defines a nonempty interval of possible values for $u^{\prime}(w) / u^{\prime}(0)$, all of which are less than one (as is required by the strict concavity of $u(\cdot)$ ).

We can then show that the following processes describe a rational expectations equilibrium with valued fiat money. Let $q^{*}, q^{* *}$ be the unique quantities satisfying

$$
\begin{aligned}
& \frac{u^{\prime}\left(w-q^{*}\right)}{u^{\prime}\left(q^{*}\right)}=\frac{\beta \pi}{1-\beta+\beta \pi}, \\
& q^{* *}=\frac{u^{\prime}\left(w-q^{*}\right) q^{*}}{u^{\prime}(w)} .
\end{aligned}
$$

Note that (4.3a) has a unique solution $0<q^{*}<w$, given the second inequality in (4.2). Then (4.3b) has a unique solution for $q^{* *}$ as well; also, the concavity of $u(\cdot)$ implies that $q^{* *}>q^{*}$. In the equilibrium, for each node $s^{t} \in N, t \geq 1$ :

(i) if $s_{t}=\xi$ and $s_{t-1}=\xi, \bar{c}^{1}\left(s^{t}\right)=0, \bar{c}^{2}\left(s^{t}\right)=w, \bar{z}^{1}\left(s^{t}\right)=0, \bar{z}^{2}\left(s^{t}\right)=1, q\left(s^{t}\right)$ $=q^{* *}$;

(ii) if $s_{t}=\xi$ and $s_{t-1}=\eta, \bar{c}^{1}\left(s^{t}\right)=q^{*}, \bar{c}^{2}\left(s^{t}\right)=w-q^{*}, \bar{z}^{1}\left(s^{t}\right)=0, \bar{z}^{2}\left(s^{t}\right)=1$, $q\left(s^{t}\right)=q^{*}$;

(iii) if $s_{t}=\eta$ and $s_{t-1}=\xi, \bar{c}^{1}\left(s^{t}\right)=w-q^{*}, \bar{c}^{2}\left(s^{t}\right)=q^{*}, \bar{z}^{1}\left(s^{t}\right)=1, \bar{z}^{2}\left(s^{t}\right)=0$, $q\left(s^{t}\right)=q^{*} ;$ and

(iv) if $s_{t}=\eta$ and $s_{t-1}=\eta, \bar{c}^{1}\left(s^{t}\right)=w, \bar{c}^{2}\left(s^{t}\right)=0, \bar{z}^{1}\left(s^{t}\right)=1, \bar{z}^{2}\left(s^{t}\right)=0, q\left(s^{t}\right)$ $=q^{* *}$.

For $t=0$, the same rules apply, but the clause "if $s_{t-1}=\xi$ " is replaced by "if $\bar{z}^{2}\left(s^{0}\right)=1$," and the clause "if $s_{t-1}=\eta$ " by "if $\bar{z}^{1}\left(s^{0}\right)=1$."

In other words, in this equilibrium, at the end of trading at each node, the entire money supply is held by the household that had a positive endowment at that node; the household with no endowment spends during the period any money that it holds at the beginning of the period. The exchange value of money is $q^{*}$ if the household that holds the entire money supply at the beginning of the period is the household with zero endowment, while it is $q^{* *}$ if the household with the money has endowment $w$. At any time, equilibrium is 
completely determined by the current distribution of money holdings and the current distribution of endowments, and those two quantities evolve as a finite-state Markov chain.

It is obvious that the situation just described satisfies the budget constraints and market clearing conditions. It remains only to demonstrate that it represents optimal consumption/portfolio behavior for each household, given the equilibrium price process $\left\{q\left(s^{t}\right)\right\}$. For the sake of brevity, this exercise is omitted here. We refer the reader to our previous paper (Santos and Woodford (1993)), where we exhibit a system of Lagrange multipliers that satisfy the standard Kuhn-Tucker first-order conditions, which in our concave problem are sufficient for the existence of an optimal plan. Thus, these processes define an equilibrium.

Observe that the existence of a finite number of households does not imply that $\underline{\pi}_{w}\left(s^{t}\right)<+\infty$ for all $s^{t}$. In this case the value of the aggregate endowment is infinite when valued using any state prices satisfying (2.1). (This is not accidental, as all other assumptions of Theorem 3.3 hold true here, and that result would otherwise imply the nonexistence of a pricing bubble in such an economy.) Of course, this is equally true of Example 4.2. What is different here is that with incomplete markets monetary equilibria are possible even with borrowing limits of the form (2.8). For each household, $\underline{\pi}_{w^{h}}\left(s^{t}\right)<+\infty$, by Proposition 2.3. But the particular state prices that make the present value of household 1's endowment finite imply an infinite value for the present value of household 2's endowment, and vice versa. This is possible only because of boundary endowments and incomplete markets.

All of our previous examples have been cases in which a pricing bubble unambiguously exists. In each case, the "fundamental" value of the security in question has been unequivocally defined, either because of the existence of complete markets, or because the security is fiat money. But in the case of incomplete markets, the "fundamental" value need not be unambiguously defined. The following example illustrates this possibility, in the case of an economy satisfying the hypotheses of Theorem 3.1 and Corollary 3.4.

EXAMPLE 4.5: Again there is realized a random state $s_{t} \in\{\xi, \eta\}$ at each date $t \geq 1$. In the present case, we assume that this random variable is independently and identically distributed at each date, with

$$
\operatorname{Prob}\left(s_{t}=\xi\right)=\operatorname{Prob}\left(s_{t}=\eta\right)=1 / 2 .
$$

A node $s^{t} \in N$ is identified with a sequence $\left\{s_{1}, \ldots, s_{t}\right\} \in\{\xi, \eta\}^{t}$, if $t \geq 1$, and with the null sequence in the case of $s^{0}$. There is a single consumption good at each node, and a single security is traded, a perpetuity paying a constant dividend forever, defined by $d\left(s^{t}\right)=1, b\left(s^{t}\right)=1$, for each $s^{t} \in N$ with $t \geq 1$. The perpetuity exists in a net supply of one unit at all times. 
The economy consists of a single representative household, with preferences of the form (4.1), where $u(\cdot)$ is again a bounded, increasing, concave $C^{1}$ function, defined on $\mathscr{R}_{+}$. But in contrast to the preceding example, the stochastic discount factor $\left\{\beta\left(s^{t}\right)\right\}$ is now defined by

$$
\beta\left(s^{t}\right)=\left(\frac{\delta}{1+r}\right)^{t}
$$

if $s_{\tau}=\eta$ for all $\tau \leq t$, or if $t=0$, while

$$
\beta\left(s^{t}\right)=\frac{\delta^{j}}{(1+r)^{t}}\left[2-\delta+2^{j+1}(1+r)^{j} r(1-\delta) \Delta\right]
$$

if $s_{\tau}=\eta$ for all $\tau \leq j$, but $s_{j+1}=\xi$, for some $0 \leq j \leq t-1$. Here $0<\delta<1$, and $r, \Delta>0$. Note that this specification of the discount factor process implies that

$$
\sum_{t=0}^{\infty} \sum_{s^{t}} \pi\left(s^{t}\right) \beta\left(s^{t}\right)=\left(\frac{1+r}{r}\right)+\Delta<+\infty
$$

so that preferences are increasing and continuous in the product topology.

The household has no endowment other than its initial endowment of the perpetuity, at any node after the initial one; specifically, $w\left(s^{0}\right)=1, w\left(s^{t}\right)=0$ for all $s^{t}$ with $t \geq 1$, and $\tilde{z}\left(s^{0}\right)=1$. It trades at all nodes $s^{t} \in N$. Finally, its borrowing limit is of the form (2.8), given by $B\left(s^{t}\right)=\underline{\pi}_{w^{h}}\left(s^{t}\right)=0$ for all $s^{t} \in N$.

Equilibrium is obviously unique, with the equilibrium allocation given by $\bar{c}\left(s^{t}\right)=1$ for each $s^{t} \in N$, and with the equilibrium price process for the perpetuity given by

$$
\begin{aligned}
q\left(s^{t}\right) & =\left[\beta\left(s^{t}\right) u^{\prime}\left(\bar{c}\left(s^{t}\right)\right)\right]^{-1} \sum_{T=t+1}^{\infty} \sum_{s^{T}} \pi\left(s^{T} \mid s^{t}\right) \beta\left(s^{T}\right) u^{\prime}\left(\bar{c}\left(s^{T}\right)\right) \\
& =\beta\left(s^{t}\right)^{-1} \sum_{T=t+1}^{\infty} \sum_{s^{T}} 2^{t-T} \beta\left(s^{T}\right)
\end{aligned}
$$

for each $s^{t} \in N$. From the above specification of the discount factor process, one finds that

$$
q\left(s^{t}\right)=\frac{1}{r}+\Delta[2(1+r)]^{t}
$$

if $s_{\tau}=\eta$ for all $\tau \leq t$, or if $t=0$, while

(4.4b) $\quad q\left(s^{t}\right)=\frac{1}{r}$

if $s_{\tau}=\xi$ for any $\tau \leq t$.

This economy satisfies at the given equilibrium all the conditions in Theorem 3.1, but violates (A.2) in Theorem 3.3 due to the nonstationarity of the stochastic 
discount factor. By Theorem 3.1 there must exist a state-price process in terms of which the price of the security equals its fundamental value. This is obviously true for the process

$$
a\left(s^{t}\right)=2^{-t} \beta\left(s^{t}\right) .
$$

On the other hand, there also exist other state-price processes, equally consistent with (2.1), in terms of which the price process (4.4) involves a speculative bubble. One such process is

$$
a\left(s^{t}\right)=[2(1+r)]^{-t} \text {. }
$$

This is consistent with (2.1), since the process (4.4) satisfies the stochastic difference equation

$$
q\left(s^{t}\right)=(1+r)^{-1} \sum_{s^{t+1} \mid s^{t}} \pi\left(s^{t+1} \mid s^{t}\right)\left[1+q\left(s^{t+1}\right)\right] .
$$

But in terms of the state prices (4.5), the fundamental value of the perpetuity is always $1 / r$, so that at any node $s^{t}$ such that $s_{\tau}=\eta$ for all $\tau \leq t$, there exists a bubble component to the perpetuity's market value, equal to

$$
\sigma\left(s^{t}\right)=\Delta[2(1+r)]^{t} .
$$

At all other nodes, the bubble component is zero. Under this interpretation, one observes a "stochastic bubble" of the kind discussed by Blanchard (1979) and many subsequent authors. There is a bubble of size $\Delta>0$ at date zero, which then grows at the rate $2(1+r)$ if $s_{t}=\eta$ each period. If ever $s_{t}=\xi$, the bubble "bursts," and is equal to zero thereafter.

This example illustrates that the classification of solutions of the form (4.6) as "fundamental" or "bubble solutions" along the lines often established is not necessarily desirable in an incomplete markets framework. Theorem 3.3 shows, however, that if agents are sufficiently impatient, then there unambiguously does not exist a pricing bubble for those types of securities in such economies.

A final remark is in order. One sometimes sees it asserted that a necessary condition for bubbles to exist is that the economy be "dynamically inefficient." Theorem 3.1 has something of this flavor, for in the case of complete markets and borrowing limits of the form (2.8), the condition that $\pi_{w}\left(s^{t}\right)<+\infty$ for each $s^{t}$ in $N$ is a sufficient condition for Pareto optimality of equilibrium. But the Theorem does not say that Pareto optimality implies the absence of bubbles. The condition referred to is not necessary for Pareto optimality, and Example 4.1 shows that a pricing bubble may exist in a Pareto optimal equilibrium. Conversely, the condition does not imply Pareto optimality in the case of incomplete markets or binding borrowing constraints; yet the theorem rules out bubbles in these cases as well. The connection between inefficiency and the existence of pricing bubbles is thus a rather loose one (see Santos and Woodford (1993) for further discussion). 


\section{CONCLUDING REMARKS}

This paper contains a fairly systematic study of the conditions under which rational asset pricing bubbles may occur in an infinite-horizon competitive framework. Our analysis has gone beyond the standard perfect capital markets paradigm, and has explored how the interaction of several conditions such as sequentially incomplete markets, productive assets, arbitrary borrowing limits and incomplete participation of agents in the entire sequence of markets, affects the possibility of asset pricing bubbles in a given equilibrium. These extensions of the standard competitive framework are commonplace in the modern finance and macroeconomics literatures.

As part of our inquiry we have developed a theory of valuation of arbitrary income streams over an infinite horizon as a consequence of the absence of arbitrage opportunities. These results should be useful more generally in the characterization of budget sets and equilibria. Furthermore, these developments of arbitrage pricing theory are readily extended to account for additional types of frictions often proposed such as liquidity and short-sale constraints, and reserve requirements.

Our main results show the nonexistence of asset pricing bubbles under fairly general assumptions. More specifically, if traded assets are sufficiently productive (i.e., the aggregate endowment is bounded by a portfolio trading plan), then for securities in positive net supply pricing bubbles do not occur, regardless of the presence of sequentially incomplete markets, arbitrary borrowing limits and incomplete participation of households in the infinite sequence of spot markets. All these extensions of the basic theory may only be compatible with a pricing bubble in additional situations if the economy is not sufficiently productive, and as a result of these restrictions aggregate wealth is infinite-valued in the given equilibrium. It should be remarked though that under sequentially incomplete markets the fundamental value of a given security may not be unambiguously defined, and even in very simple cases a bubble may be possible for some state-price processes. As shown in Theorem 3.3, however, this pathology ceases to exist if agents are sufficiently impatient.

These results suggest that known examples of pricing bubbles depend upon rather special circumstances. In consequence, familiar examples (such as the overlapping generations model of Samuelson (1958) or the Bewley (1980) model) seem to be quite fragile as potential foundations for monetary theory. For when these models are extended to allow for trading in additional assets that are sufficiently productive (in particular, capital earning returns satisfying the criterion of Abel et al.), or to include an infinitely lived household (or Barro "dynasty") that is able to borrow against its future endowment and that owns a fraction of aggregate wealth, pricing bubbles-and hence monetary equilibria - can be excluded under quite general assumptions. We conclude from this that robust monetary equilibria depend upon the presence of additional trading restrictions. As shown in a companion paper (Santos and Woodford (1995)), in such kind of models the fundamental value of an asset can 
be extended to include the shadow value of relaxation of the constraints, and in consequence monetary equilibria are not usefully thought of as pricing bubbles.

Finally, we would like to emphasize that our results excluding the possibility of rational pricing bubbles do not imply that there should be no role for an effect of self-fulfilling expectations upon asset prices and equilibrium allocations. While examples of multiple equilibria and "sunspot" equilibria are loosely referred to as "bubbles," there is generally no close analytical connection between these phenomena and the existence of a pricing bubble in our sense. In particular, the presence of assets sufficiently productive to ensure a finite value for the economy's aggregate endowment does not exclude the possibility that equilibrium is indeterminate, or that sunspot equilibria exist, as we discuss further in Santos and Woodford (1993).

Centro de Investigación Económica, ITAM, Av. Camino a Santa Teresa no. 930, Col. Heroes de Padierna, Mexico City D.F. 10700, Mexico

and

Dept. of Economics, Princeton University, Princeton, NJ 08544, U.S.A.

Manuscript received December, 1993; final revision received May, 1996.

\section{APPENDIX}

Proof of Proposition 2.2: (i) We first establish that $\bar{\pi}_{x}\left(s^{t}\right) \geq \bar{v}_{x}\left(s^{t}\right)$, where $\bar{v}_{x}\left(s^{t}\right) \equiv$ $\sup _{a \in A\left(s^{t}\right)} v_{x}\left(s^{t} ; p, a\right)$. Let $a$ be any element of $A\left(s^{t}\right)$, and let $z$ be any plan satisfying conditions (2.6). Then it suffices to show that

$$
q\left(s^{t}\right)^{\prime} z\left(s^{t}\right) \geq v_{x}\left(s^{t} ; p, a\right) .
$$

Multiplication of the left- and right-hand sides of (2.6a) by $a\left(s^{r}\right)$, and summing over $s^{r} \mid s^{r-1}$ for some $s^{r-1}$ yields

$$
a\left(s^{r-1}\right) q\left(s^{r-1}\right)^{\prime} z\left(s^{r-1}\right) \geq \sum_{s^{r} \mid s^{r-1}} a\left(s^{r}\right)\left[p\left(s^{r}\right)^{\prime} x\left(s^{r}\right)+q\left(s^{r}\right)^{\prime} z\left(s^{r}\right)\right]
$$

using (2.1). Repetition of this argument for each $t+1 \leq r \leq T$ and each $s^{r} \mid s^{t}$, for arbitrary $T$, and summing over all those nodes, yields

$$
\begin{aligned}
a\left(s^{t}\right) q\left(s^{t}\right)^{\prime} z\left(s^{t}\right) & \geq \sum_{r=t+1}^{T} \sum_{s^{r} \mid s^{t}} a\left(s^{r}\right) p\left(s^{r}\right)^{\prime} x\left(s^{r}\right)+\sum_{s^{T} \mid s^{t}} a\left(s^{T}\right) q\left(s^{T}\right)^{\prime} z\left(s^{T}\right) \\
& \geq \sum_{r=t+1}^{T} \sum_{s^{r} \mid s^{t}} a\left(s^{r}\right) p\left(s^{r}\right)^{\prime} x\left(s^{r}\right)
\end{aligned}
$$

using (2.6b). As this bound holds for all $T>t$, and the right-hand side is a nondecreasing series in $T$, there must exist a well-defined limit of the right-hand side as $T \rightarrow+\infty$, and it must satisfy the same bound, so that (6.1) holds.

(ii) Next we establish that $\bar{\pi}_{x}\left(s^{t}\right) \leq \bar{v}_{x}\left(s^{t}\right)$. This is only nontrivial if $\bar{v}_{x}\left(s^{t}\right)<+\infty$, so we assume that this is the case. It then suffices to exhibit a plan $z$ satisfying conditions (2.6) such that

$$
q\left(s^{t}\right)^{\prime} z\left(s^{t}\right)=\bar{v}_{x}\left(s^{t}\right)
$$


We construct such plan as follows. For any $s^{r} \mid s^{t}$, consider the minimization problem

$$
W(y) \equiv \inf _{z \in \mathscr{R}^{k\left(s^{\prime}\right)}} q\left(s^{r}\right)^{\prime} z
$$

such that $R\left(s^{r+1}\right)^{\prime} z \geq y\left(s^{r+1}\right)$ for each $s^{r+1} \mid s^{r}$, where $y$ is a specification of required wealth $y\left(s^{r+1}\right)$ at each of the nodes $s^{r+1} \mid s^{r}$. We establish below that for the case

$$
\bar{y}\left(s^{r+1}\right)=p\left(s^{r+1}\right)^{\prime} x\left(s^{r+1}\right)+\bar{v}_{x}\left(s^{r+1}\right)
$$

this problem has a solution provided that $y\left(s^{r+1}\right)=0$ for all $s^{r+1} \mid s^{r}$ such that $R\left(s^{r+1}\right)=0$; moreover, the minimized value satisfies

$$
W(\bar{y})=\bar{v}_{x}\left(s^{r}\right) \geq 0 .
$$

Let $\bar{z}\left(s^{r}\right)$ denote a portfolio at node $s^{r}$ that solves this problem. Then the plan $z$ given by $z\left(s^{r}\right)=\bar{z}\left(s^{r}\right)$ for each $s^{r} \mid s^{t}$ satisfies (2.6) at all nodes, and satisfies (6.2) as well. Thus (2.7a) is established.

(iii) It remains to establish the existence of a solution to (6.3) that satisfies (6.4). Note that (6.3) is a general linear programming problem of the sort treated in Gale (1960, Ch. 3). The corresponding dual problem is

$$
V(y)=\sup _{\lambda \in \mathscr{R}_{+}^{m\left(s^{r}\right)}} \sum_{s^{r+1} \mid s^{r}} \lambda\left(s^{r+1}\right) y\left(s^{r+1}\right)
$$

such that

$$
\sum_{s^{r+1} \mid s^{r}} \lambda\left(s^{r+1}\right) R\left(s^{r+1}\right)^{\prime}=q\left(s^{r}\right)^{\prime}
$$

(Note that the constraints in (6.6) hold with equality because there are no nonnegative constraints on $z$ in (6.3).) If $y\left(s^{r+1}\right)=0$ for all $s^{r+1} \mid s^{r}$ such that $R\left(s^{r+1}\right)=0$, one observes that there exist vectors $z$ such that $R\left(s^{r+1}\right)^{\prime} z \geq y\left(s^{r+1}\right)$, so that problem (6.3) is feasible. Furthermore, the absence of arbitrage opportunities implies that there exist vectors $\lambda \geq 0$ that satisfy (6.6); this follows from the existence of state prices satisfying (2.1). Hence both problem (6.3) and its dual (6.5) are feasible. It then follows from the duality theorem of linear programming (Gale (1960, Theorem 3.1)) that optima exist for both problems, and that $W(y)=V(y)$. By continuity, the supremum in (6.5) remains the same if one adds the restriction that $\lambda \gg 0$. Thus

$$
W(y)=\sup _{\lambda \in \Lambda\left(s^{r}\right)} \sum_{s^{r+1} \mid s^{r}} \lambda\left(s^{r+1}\right) y\left(s^{r+1}\right)
$$

where $\Lambda\left(s^{r}\right)$ is the subset of $\lambda \in \mathscr{R}_{++}^{m\left(s^{t}\right)}$ for which (6.6) holds.

We then observe that the maximization problem defining $\bar{v}_{x}\left(s^{t}\right)$ implies, using a dynamic programming argument, that

$$
\bar{v}_{x}\left(s^{r}\right)=\sum_{s^{r+1} \mid s^{r}} \bar{\lambda}\left(s^{r+1}\right) \bar{y}\left(s^{r+1}\right)
$$

for each $s^{r} \mid s^{t}$. Comparing this expression with (6.7) yields (6.4). This completes the proof of (2.7a).

(iv) Next we establish (2.7b). The proof is similar to that in part (i). Consider any state-price process $a \in A\left(s^{t}\right)$, and any plan $z$ satisfying conditions (i)-(ii) of the definition of $\underline{\pi}_{x}\left(s^{t}\right)$. Multiplication of both sides of (2.5) by $a\left(s^{r}\right)$, and summing over all nodes $s^{r} \mid s^{t}$ with dates $t+1 \leq r \leq T$, yields

$$
\sum_{r=t+1}^{T} \sum_{s^{r} \mid s^{t}} a\left(s^{r}\right) p\left(s^{r}\right)^{\prime} x\left(s^{r}\right) \geq \sum_{s^{T} \mid s^{t}} a\left(s^{T}\right) q\left(s^{T}\right)^{\prime} z\left(s^{T}\right)-a\left(s^{t}\right) q\left(s^{t}\right)^{\prime} z\left(s^{t}\right),
$$


using (2.1). But then the facts that $q\left(s^{T}\right)^{\prime} z\left(s^{T}\right) \geq 0$ for each $s^{T} \mid s^{t}$, and that $p\left(s^{r}\right)^{\prime} x\left(s^{r}\right) \geq 0$ for each $s^{r} \mid s^{t}$ with $r>T$, imply that $v_{x}\left(s^{t} ; p, a\right) \geq-q\left(s^{t}\right)^{\prime} z\left(s^{t}\right)$. Then the definition of $\underline{\pi}_{x}\left(s^{t}\right)$ implies (2.7b).

(v) Finally, we establish $(2.7 \mathrm{c})$ under the additional hypothesis. For this purpose, we show that for arbitrary $\varepsilon>0$ it is possible to construct a state-price process $\bar{a} \in A\left(s^{t}\right)$ such that $v_{x}\left(s^{t} ; p, \bar{a}\right) \leq$ $\underline{\pi}_{x}\left(s^{t}\right)+\varepsilon$.

We first observe that, if $\underline{\pi}_{x}\left(s^{r+1}\right)<+\infty$ for all $s^{r+1} \mid s^{r}$, then

$$
\underline{\pi}_{x}\left(s^{r}\right)=\min _{\lambda} \sum_{s^{r+1} \mid s^{r}} \lambda\left(s^{r+1}\right)\left[p\left(s^{r+1}\right)^{\prime} x\left(s^{r+1}\right)+\underline{\pi}_{x}\left(s^{r+1}\right)\right]
$$

where the minimization is over the set of nonnegative multipliers $\lambda$ satisfying (6.6). (The proof of (6.8) follows similar steps as that of part (iii), and it is therefore omitted; for further details, see Santos and Woodford (1993).) Then (6.8) holds at all $s^{r} \mid s^{t}$ under the additional hypothesis asserted in $(2.7 \mathrm{c})$, and the minimum is achieved for some set of nonnegative multipliers $\left\{\bar{\lambda}\left(s^{r+1} \mid s^{r}\right)\right\}$. Hence, for every $T_{1}>t$ there exists a nonnegative system $\left\{\bar{\varphi}\left(s^{r+1} \mid s^{r}\right)\right\}$, where $\bar{\varphi}\left(s^{r} \mid s^{t}\right)$ is defined recursively as $\bar{\varphi}\left(s^{r} \mid s^{t}\right)=\bar{\lambda}\left(s^{r}\right) \bar{\varphi}\left(s^{r}-1 \mid s^{t}\right)$ and $\bar{\varphi}\left(s^{t}\right)=1$, such that

$$
\underline{\pi}_{x}\left(s^{t}\right)=\sum_{r=t+1}^{T_{1}} \sum_{s^{r} \mid s^{t}} \bar{\varphi}\left(s^{r}\right) p\left(s^{r}\right)^{\prime} x\left(s^{r}\right)+\sum_{s^{T_{1} \mid s^{t}}} \bar{\varphi}\left(s^{T_{1}}\right) \underline{\pi}_{x}\left(s^{T_{1}}\right) .
$$

Moreover, since all terms of the form $p\left(s^{r}\right)^{\gamma} x\left(s^{r}\right)$ and $\underline{\pi}_{x}\left(s^{T_{1}}\right)$ in (6.9) are finite, for every $\varepsilon>0$ there exists a system of state prices $\left\{\bar{a}\left(s^{r} \mid s^{t}\right)\right\}$, defined recursively as $\bar{a}\left(s^{r} \mid s^{t}\right)=\lambda\left(s^{r}\right) \bar{a}\left(s^{r}-1 \mid s^{t}\right)$, for positive $\left\{\lambda\left(s^{r}\right)\right\} \in \Lambda\left(s^{r}-1\right)$ and $\bar{a}\left(s^{t}\right)=1$, such that

$$
\underline{\pi}_{x}\left(s^{t}\right)+\frac{\varepsilon}{2} \geq \sum_{r=t+1}^{T_{1}} \sum_{s^{r} \mid s^{t}} \bar{a}\left(s^{r}\right) p\left(s^{r}\right)^{\prime} x\left(s^{r}\right)+\sum_{s^{T_{1} \mid s^{t}}} \bar{a}\left(s^{T_{1}}\right) \underline{\pi}_{x}\left(s^{T_{1}}\right) .
$$

By the same argument, for an arbitrary $T_{2}>T_{1}$ and $\varepsilon / 4>0$ it follows that there are state prices $\left\{\bar{a}\left(s^{r} \mid s^{T_{1}}\right)\right\}$ such that

$$
\sum_{s^{T_{1} \mid s^{t}}} \bar{a}\left(s^{T_{1}}\right) \underline{\pi}_{x}\left(s^{T_{1}}\right)+\frac{\varepsilon}{4} \geq \sum_{r=T_{1}+1}^{T_{2}} \sum_{s^{r} \mid s^{t}} \bar{a}\left(s^{r}\right) p\left(s^{r}\right)^{\prime} x\left(s^{r}\right)+\sum_{s^{T_{2} \mid s^{t}}} \bar{a}\left(s^{T_{2}}\right) \underline{\pi}_{x}\left(s^{T_{2}}\right) .
$$

Proceeding inductively, we find that

$$
\underline{\pi}_{x}\left(s^{t}\right)+\varepsilon \geq \sum_{r=t+1}^{\infty} \sum_{s^{r} \mid s^{t}} \bar{a}\left(s^{r}\right) p\left(s^{r}\right)^{\prime} x\left(s^{r}\right)
$$

which implies that $\underline{\pi}_{x}\left(s^{t}\right)+\varepsilon \geq v_{x}\left(s^{t} ; p, \bar{a}\right)$. This establishes (2.7c).

Q.E.D.

ProOf OF Proposition 2.3: (i) We shall show that there cannot be an optimal plan for household $h$ if $\underline{\pi}_{w} h\left(s^{t}\right)=+\infty$ for some $s^{t} \in N^{h} \backslash \bar{N}^{h}$. This will establish that $\underline{\pi}_{w}\left(s^{t}\right)<+\infty$. Moreover, if $\underline{\pi}_{w} h\left(s^{t}\right)<+\infty$ for each $s^{t} \in N^{h} \backslash \bar{N}^{h}$, then by Proposition 2.2 the borrowing limit $B^{h}\left(s^{t}\right)$ can be equivalently expressed as

$$
\inf _{a \in A\left(s^{t}\right)} v_{w^{h}}\left(s^{t} ; p, a\right)<+\infty .
$$

(ii) We first observe that for each $s^{t} \in N^{h} \backslash \bar{N}^{h}$ at which $\underline{\pi}_{w^{h}}\left(s^{t}\right)=+\infty$, there exists at least one immediate successor $s^{t+1}$ at which $\underline{\pi}_{w^{h}}\left(s^{t+1}\right)=+\infty$ as well. (For if there were none, (6.8) could be used to show that $\underline{\pi}_{w} h\left(s^{t}\right)<+\infty$.) For any such node $s^{t}$, let $F\left(s^{t}\right)$ denote the set of immediate successors at which the borrowing limit is similarly infinite. It is shown below that there also must exist a portfolio $\tilde{z}\left(s^{t}\right) \in \mathscr{R}^{k\left(s^{t}\right)}$ such that $q\left(s^{t}\right)^{\prime} \tilde{z}\left(s^{t}\right)<0$, yet with the property that

$$
R\left(s^{t+1}\right)^{\prime} \tilde{z}\left(s^{t}\right) \geq 0
$$

for all $s^{t+1} \notin F\left(s^{t}\right)$. 
Then no consumption/portfolio plan $\left(c^{h}, z^{h}\right)$ can be optimal for $h$, since it is possible for $h$ to consume a strictly greater vector at node $s^{t}$, without reducing consumption at any successor nodes of $s^{t}$, financing the additional consumption by purchasing a sufficient quantity of the portfolio $\tilde{z}\left(s^{t}\right)$. This does not violate (1.1c), given that the borrowing limit is infinite at this node. As this portfolio change entails that $R\left(s^{t+1}\right) \tilde{z}\left(s^{t}\right) \geq 0$ at any successor node $s^{t+1} \notin F\left(s^{t}\right)$, it is not necessary to change consumption or the portfolio at any such node. Furthermore, at any successor node $s^{t+1} \in F\left(s^{t}\right)$, the borrowing limit is again infinite. Thus one can proceed iteratively to construct an alternative portfolio plan that satisfies budget constraints (1.1) at all nodes, in the case of a consumption plan that differs from $c^{h}$ in the increased consumption at $s^{t}$, and possibly at some subsequent nodes. Since this alternative consumption plan must be preferred by (A.1), $c^{h}$ is evidently not optimal.

(iii) It remains to show the existence of a portfolio $\tilde{z}\left(s^{t}\right)$ that satisfies (6.10). From the definition of $\underline{\pi}_{w^{h}}\left(s^{t}\right)$, it follows that if $\underline{\pi}_{w^{h}}\left(s^{t}\right)=+\infty$ then there exists a sequence of finite portfolios $\left\{z^{n}\right\}_{n=1}^{\infty}$, with the property that $-q\left(s^{t}\right) z^{n}$ converges to $+\infty$, as $n$ goes to $+\infty$, and $-R\left(s^{t+1}\right) z^{n} \leq$ $p\left(s^{t+1}\right) w^{h}\left(s^{t+1}\right)+\underline{\pi}_{w}\left(s^{t+1}\right)$ for every $n$ and every $s^{t+1} \notin F\left(s^{t}\right)$. Consider now the alternative sequence

$$
\left\{\frac{z^{n}}{\left|q\left(s^{t}\right)^{\prime} z^{n}\right|}\right\}_{n=1}^{\infty}
$$

Then for every $\varepsilon>0$,

$$
\frac{q\left(s^{t}\right)^{\prime} z^{n}}{\left|q\left(s^{t}\right)^{\prime} z^{n}\right|}=-1 \text { and } \frac{-R\left(s^{t+1}\right)^{\prime} z^{n}}{\left|q\left(s^{t}\right)^{\prime} z^{n}\right|} \leq \varepsilon
$$

for all $s^{t+1} \notin F\left(s^{t}\right)$ and large enough $n$.

Let $\hat{z}=(1,1, \ldots, 1)$ be the portfolio involving one unit of each security. Let $\lambda>0$ be such that $q\left(s^{t}\right)(\hat{z} / \lambda)<1$. For $n=1,2, \ldots$, define

$$
\tilde{z}^{n}=\left(\frac{z^{n}}{\left|q\left(s^{t}\right)^{\prime} z^{n}\right|}+\frac{\hat{z}}{\lambda}\right) .
$$

Then $q\left(s^{t}\right) \tilde{z}^{n}<0$ for all $n \geq 1$. Furthermore, by construction, $R\left(s^{t+1}\right) \tilde{z}^{n} \geq 0$ for all $s^{t+1} \notin F\left(s^{t}\right)$ and large enough $n$.

Q.E.D.

Proof of Lemma 3.6: Suppose instead that $q\left(s^{t}\right)^{h} \bar{z}^{h}\left(s^{t}\right)$ exceeds the upper bound stated. Then there exists a portfolio trading plan $z$ with

$$
q\left(s^{t}\right)^{\prime} z\left(s^{t}\right)<q\left(s^{t}\right)^{\prime} \bar{z}^{h}\left(s^{t}\right)
$$

such that the joint plan $\left(\bar{c}^{h}, z\right)$ satisfies (1.1a) and

(6.11b) $\quad q\left(s^{T}\right)^{\prime} z\left(s^{T}\right) \geq 0$

for all $s^{T} \mid s^{t}$ with $T>t$. This follows from the definition of $\bar{\pi}_{\left(\bar{c}^{h}-w^{h}\right)^{+}}\left(s^{t}\right)$, and the fact that $\bar{c}^{h}\left(s^{T}\right) \leq w^{h}\left(s^{T}\right)+\left(\bar{c}^{h}-w^{h}\right)^{+}\left(s^{T}\right)$.

Then define a plan $\tilde{z}^{h}$ for the nodes $s^{T} \in N^{h}$ by setting $\tilde{z}^{h}\left(s^{T}\right)=\bar{z}^{h}\left(s^{T}\right)$ except on the subtree $s^{T} \mid s^{t}$, where $\tilde{z}^{h}\left(s^{T}\right)=z\left(s^{T}\right)$ for $s^{T} \mid s^{t}$ such that $s^{T} \in N^{h} \backslash \bar{N}^{h}$, and $\tilde{z}^{h}\left(s^{T}\right)=0$ for $s^{T} \mid s^{t} \in \bar{N}^{h}$. It follows from (6.11b) that the substitution of 0 for $z\left(s^{t}\right)$ at nodes $s^{T} \mid s^{t} \in \bar{N}^{h}$ does not lead to violation of (1.1a). Thus the joint plan $\left(\bar{c}^{h}, \tilde{z}^{h}\right)$ satisfies (1.1a)-(1.1b). Furthermore, (6.11b) implies that it satisfies (1.1c) at each $s^{T} \in N^{h} \backslash \bar{N}^{h}$ as well, since $B^{h}\left(s^{T}\right) \geq 0$ at each such node. Finally, (6.11a) implies that (1.1a) is a strict inequality for this plan at node $s^{t}$. Thus it is possible to increase consumption at node $s^{t}$ without lowering it at any other node, which by (A.1) must be preferred. But this contradicts the hypothesis that $\left(\bar{c}^{h}, \bar{z}^{h}\right)$ is optimal for $h$ given prices $(p, q)$.

Q.E.D. 
Proof of Lemma 3.7: (i) We first establish that for any $\varepsilon>0$, there exists a date $\hat{T}>0$, and a set of state prices $\bar{a} \in A\left(s^{t}\right)$ such that

$$
\frac{1}{\bar{a}\left(s^{t}\right)} \sum_{s^{T} \mid s^{t}} \bar{a}\left(s^{T}\right) \bar{\pi}_{\tilde{w}}\left(s^{T}\right) \leq \varepsilon
$$

for all $T \geq \hat{T}$. As pointed out in Section 2, if $\bar{\pi}_{w}\left(s^{t}\right)<+\infty$ then $\bar{\pi}_{\tilde{w}}\left(s^{t}\right)<+\infty$ as well. Proposition 2.2 then entails that for every $\varepsilon>0$ there must exist some $\bar{a} \in A\left(s^{t}\right)$ such that $v_{\tilde{w}}^{\prime}\left(s^{t} ; p, \bar{a}\right)>\bar{\pi}_{\tilde{w}}\left(s^{t}\right)-\varepsilon$. Accordingly, there must exist a date $\hat{T}$ such that

$$
\frac{1}{\bar{a}\left(s^{t}\right)} \sum_{r=t+1}^{T} \sum_{s^{r} \mid s^{t}} \bar{a}\left(s^{r}\right) p\left(s^{r}\right)^{\prime} \tilde{w}\left(s^{r}\right)>\bar{\pi}_{\tilde{w}}\left(s^{t}\right)-\varepsilon
$$

for all $T \geq \hat{T}$. But the proof of Proposition 2.2 also implies that

$$
\bar{\pi}_{\tilde{w}}\left(s^{t}\right) \geq \frac{1}{\bar{a}\left(s^{t}\right)} \sum_{r=t+1}^{T} \sum_{s^{r} \mid s^{t}} \bar{a}\left(s^{r}\right) p\left(s^{r}\right)^{\prime} \tilde{w}\left(s^{r}\right)+\frac{1}{\bar{a}\left(s^{t}\right)} \sum_{s^{T} \mid s^{t}} \bar{a}\left(s^{T}\right) \bar{\pi}_{\bar{w}}\left(s^{T}\right) .
$$

Comparing this last expression with (6.13) shows that $\bar{a}$ is an example of a set of state prices for which (6.12) holds.

(ii) It only suffices to prove the lemma for the case in which $q\left(s^{t}\right)^{z} z\left(s^{t}\right)>0$. Given any $0<\delta<1$, let $0<\alpha, \beta<1$ be two numbers such that $\alpha \beta=\delta$. Then let $\tilde{H}\left(s^{t}\right)$ be a finite subset of $H\left(s^{t}\right)$ with the property that

$$
\sum_{h \in \tilde{H}} q\left(s^{t}\right)^{\prime} \bar{z}^{h}\left(s^{t}\right) \geq \alpha q\left(s^{t}\right)^{\prime} z\left(s^{t}\right)
$$

(Because $H\left(s^{t}\right)$ is countable and aggregate savings $q\left(s^{t}\right)^{t} z\left(s^{t}\right)$ are finite, such a finite subset must exist.) Let $\zeta\left(s^{t}\right)$ be the number of members in the finite subset $\tilde{H}\left(s^{t}\right)$. Then it follows from (6.12) that there exists a date $T$ and $\bar{a} \in A\left(s^{t}\right)$ such that

$$
\frac{1}{\bar{a}\left(s^{t}\right)} \sum_{s^{T} \mid s^{t}} \bar{a}\left(s^{T}\right) \bar{\pi}_{\tilde{w}}\left(s^{T}\right) \leq \frac{(1-\beta)}{\zeta\left(s^{t}\right)} \sum_{h \in \tilde{H}} q\left(s^{t}\right)^{\prime} \bar{z}^{h}\left(s^{t}\right) .
$$

But Lemma 3.6 implies that for any $s^{T} \mid s^{t}$,

$$
\sum_{h \in \tilde{H}} q\left(s^{T}\right)^{\prime} \bar{z}^{h}\left(s^{T}\right) \leq \sum_{h \in \tilde{H}} \bar{\pi}_{\left(\bar{c}^{h}-w^{h}\right)^{+}}\left(s^{T}\right) \leq \zeta\left(s^{t}\right) \bar{\pi}_{\tilde{w}}\left(s^{T}\right)
$$

and hence that

$$
\sum_{\substack{T \\ s^{T} \mid s^{t} \\ s^{T} \in N^{h}}} \sum_{h \in \tilde{H}} W^{h}\left(s^{T}\right) \leq \zeta\left(s^{t}\right) \sum_{s^{T} \mid s^{t}} \bar{a}\left(s^{T}\right) \bar{\pi}_{\tilde{\psi}}\left(s^{T}\right) \leq(1-\beta) \sum_{h \in \tilde{H}} W^{h}\left(s^{t}\right)
$$

introducing the notation, $W^{h}\left(s^{T}\right) \equiv \bar{a}\left(s^{T}\right) q\left(s^{T}\right)^{\prime} \bar{z}^{h}\left(s^{T}\right)$, and it is understood that the summation of the first two terms is over all $s^{T} \mid s^{t}$ at time $T$.

By Assumption (A.1), an optimal plan for any household necessarily involves the budget constraint (1.1a) being satisfied with equality at each node. Suppose that for any $h \in \tilde{H}\left(s^{t}\right)$, we multiply both sides of this equation by $\bar{a}$, and sum over all $s^{r} \mid s^{t}, s^{r} \in N^{h}$, with dates $t+1 \leq r \leq T$. Introducing the further notation

$$
\begin{aligned}
C^{h}\left(s^{r}\right) & \equiv \bar{a}\left(s^{r}\right) p\left(s^{r}\right)^{\prime} \bar{c}^{h}\left(s^{r}\right), \\
\Omega^{h}\left(s^{r}\right) & \equiv \bar{a}\left(s^{r}\right) p\left(s^{r}\right)^{\prime} w^{h}\left(s^{r}\right),
\end{aligned}
$$


we obtain

$$
\sum_{r=t+1}^{T} \sum_{\substack{s^{r} \mid s^{t} \\ s^{r} \in N^{h}}} C^{h}\left(s^{r}\right)=\sum_{r=t+1}^{T} \sum_{\substack{s^{r} \mid s^{t} \\ s^{r} \in N^{h}}} \Omega^{h}\left(s^{r}\right)+W^{h}\left(s^{t}\right)-\sum_{\substack{s^{T} \mid s^{t} \\ s^{T} \in N^{h}}} W^{h}\left(s^{T}\right) .
$$

(In cancelling all terms involving wealth in intermediate periods, we have used the restriction that $\bar{z}^{h}\left(s^{r}\right)=0$ at each $s^{r} \in \bar{N}^{h}$.) Because endowments are nonnegative, the left-hand side cannot be smaller than the sum of the two final terms on the right-hand side. Summing both sides of the inequality over the members of $\tilde{H}\left(s^{t}\right)$ and using (6.14) yields

$$
\begin{aligned}
\sum_{r=t+1}^{T} \sum_{\substack{s^{r} \mid s^{t} \\
s^{\prime} \in N^{h}}} \sum_{h \in \tilde{H}} C^{h}\left(s^{r}\right) & \geq \sum_{h \in \tilde{H}} W^{h}\left(s^{t}\right)-\sum_{\substack{s^{T} \mid s^{t} \\
s^{T} \in N^{h}}} \sum_{h \in \tilde{H}} W^{h}\left(s^{T}\right) \\
& \geq \beta \sum_{h \in \tilde{H}} W^{h}\left(s^{t}\right) \\
& \geq \delta \bar{a}\left(s^{t}\right) q\left(s^{t}\right)^{\prime} z\left(s^{t}\right) .
\end{aligned}
$$

As the value of aggregate consumption must be at least as large as the value of consumption by households in $\tilde{H}\left(s^{t}\right)$, this establishes (3.2).

Q.E.D.

The theorem is then proved as follows.

ProOF OF THEOREM 3.1: Fixing $0<\delta<1$, one first observes that one may select a system of state prices $a \in A\left(s^{t}\right)$ and a sequence of dates $\left\{T_{n}\right\}$ for $n=0,1,2, \ldots$, with $T_{0}=t, T_{n+1}>T_{n}$ for each $n$, so that for any $n$ and any node $s^{T n} \mid s^{t}$,

$$
\sum_{r=T_{n}+1}^{T_{n+1}} \sum_{s^{r} \mid s^{T n}} \sum_{h \in H\left(s^{r}\right)} C^{h}\left(s^{r}\right) \geq \delta a\left(s^{T n}\right) q\left(s^{T n}\right)^{\prime} z\left(s^{T n}\right) .
$$

The construction is recursive. Suppose, for any $n \geq 0$, that $T_{n}$ has been chosen, as well as state prices $a\left(s^{r}\right)$ for all nodes $s^{r} \mid s^{t}$ with dates $r \leq T_{n}$. (For the case $n=0$, set $T_{0}=t$ and choose an arbitrary normalization for $a\left(s^{t}\right)$.) Then consider any node $s^{T n}$. By Lemma 3.7, there exists a system of state prices $\bar{a} \in A\left(s^{T n}\right)$ and a date $T\left(s^{T n}\right)$ such that (3.2) holds, and it follows that (3.2) holds as well for all dates $T \geq T\left(s^{T n}\right)$. It is also possible to choose $\bar{a}$ so that $\bar{a}\left(s^{T n}\right)=a\left(s^{T n}\right)$, since the normalization of the state prices referred to in Lemma 3.7 is arbitrary. Then choose $T_{n+1}=$ $\max _{s} T n T\left(s^{T n}\right)$. The maximum is achieved because the set of nodes at each date is finite. Finally, for each $s^{T n}$, extend the state prices to the nodes $s^{r} \mid s^{T n}$ with dates $T_{n}+1 \leq r \leq T_{n+1}$ by setting $a\left(s^{r}\right)=\bar{a}\left(s^{r}\right)$. One may then repeat the construction, replacing $n$ by $n+1$.

Substituting conditions (1.3a)-(1.4a) into inequality (6.16) and summing over all nodes at date $T_{n}$, we obtain

$$
\sum_{s^{T n}} a\left(s^{T n}\right) q\left(s^{T n}\right)^{\prime} z\left(s^{T n}\right) \leq \delta^{-1} \sum_{r=T_{n}+1}^{T_{n+1}} \sum_{s^{r}} a\left(s^{r}\right) p\left(s^{r}\right)^{\prime} \tilde{w}\left(s^{r}\right) .
$$

Summing over $n$, we then have

$$
\sum_{n=0}^{\infty} \sum_{s^{T n}} a\left(s^{T n}\right) q\left(s^{T n}\right)^{\prime} z\left(s^{T n}\right) \leq \delta^{-1} \sum_{T=t+1}^{\infty} \sum_{s^{T}} a\left(s^{T}\right) p\left(s^{T}\right)^{\prime} \tilde{w}\left(s^{T}\right)<+\infty
$$


where use is made of the assumption that $\bar{\pi}_{w}\left(s^{t}\right)<+\infty$, and hence that $\bar{\pi}_{\tilde{w}}\left(s^{t}\right)<+\infty$ for $t=T_{0}$. Then since each term in the infinite sum on the left-hand side must be nonnegative, it follows that

$$
\lim _{n \rightarrow+\infty} \sum_{s^{T n}} a\left(s^{T n}\right) q\left(s^{T n}\right)^{\prime} z\left(s^{T n}\right)=0 .
$$

On the other hand, iterated application of (2.4) implies

$$
a\left(s^{t}\right) \sigma\left(s^{t}\right)^{\prime} z\left(s^{t}\right)=\sum_{s^{T} \mid s^{t}} a\left(s^{T}\right) \sigma\left(s^{T}\right)^{\prime} z\left(s^{T}\right) .
$$

Also, by virtue of Proposition 2.1, $q\left(s^{T}\right) \geq \sigma\left(s^{T}\right)$. Given that all the terms involved in these expressions are nonnegative, we must have $\sigma_{j}\left(s^{T}\right) z_{j}\left(s^{T}\right)=0$ for each security $j$ traded at any node $s^{T} \mid s^{t}$. Then $z_{j}\left(s^{T}\right)>0$ implies that $\sigma_{j}\left(s^{T}\right)=0$, so that there is no bubble component to the value of any security in positive net supply. The same conclusion holds for the case of any security of finite maturity as established in Section 2.

Q.E.D.

Proof of Lemma 3.8: Note first that if $N^{h}$ is a finite set, (3.3) follows immediately from (6.15) since the final term in (6.15) must vanish for large enough $T$. More generally, one can bound the size of that term, for one can show that

$$
\left(1-\gamma^{h}\right) q\left(s^{T}\right)^{\prime} \bar{z}^{h}\left(s^{T}\right) \leq p\left(s^{T}\right)^{\prime} \tilde{w}\left(s^{T}\right)
$$

for all $s^{T}$, where $\gamma^{h}$ is the factor referred to in (A.2).

For suppose that (6.17) is violated at some $s^{T} \in N^{h}$. Then another feasible plan for $h$ is $\left(\hat{c}^{h}, \hat{z}^{h}\right)$, defined by

$$
\begin{aligned}
& \left(\hat{c}_{-}^{h}\left(s^{T}\right), \hat{c}^{h}\left(s^{T}\right), \hat{c}_{+}^{h}\left(s^{T}\right)\right)=\left(\bar{c}_{-}^{h}\left(s^{T}\right), \bar{c}^{h}\left(s^{T}\right)+\tilde{w}\left(s^{T}\right), \gamma^{h} \bar{c}_{+}^{h}\left(s^{T}\right)\right), \\
& \left(\hat{z}_{-}^{h}\left(s^{T}\right), \hat{z}^{h}\left(s^{T}\right), \hat{z}_{+}^{h}\left(s^{T}\right)\right)=\left(\bar{z}_{-}^{h}\left(s^{T}\right), \gamma^{h} \bar{z}^{h}\left(s^{T}\right), \gamma^{h} \bar{z}_{+}^{h}\left(s^{T}\right)\right),
\end{aligned}
$$

using the notation introduced in (A.2). By Assumption (A.2), this alternative allocation must be preferred to $\left(\bar{c}^{h}, \bar{z}^{h}\right)$. Thus we obtain a contradiction, and so (6.17) must hold at all nodes. Substituting (6.17) into (6.15) then yields

$$
\begin{aligned}
\sum_{r=t+1}^{T} & \sum_{\substack{s^{r} \mid s^{t} \\
s^{r} \in N^{h}}} C^{h}\left(s^{r}\right)+\left(1-\gamma^{h}\right)^{-1} \sum_{\substack{s^{T} \mid s^{t} \\
s^{T} \in N^{h}}} a\left(s^{T}\right) p\left(s^{T}\right)^{\prime} \tilde{w}\left(s^{T}\right) \\
\geq & \sum_{r=t+1}^{T} \sum_{\substack{s^{r} \mid s^{\prime} \\
s^{\prime} \in N^{h}}} \Omega^{h}\left(s^{r}\right)+W^{h}\left(s^{t}\right) .
\end{aligned}
$$

Now let us take the limit of each term in the above inequality as $T \rightarrow+\infty$. The fact that $v_{w}\left(s^{t} ; p, a\right)<+\infty$ implies that $v_{w^{h}}\left(s^{t} ; p, a\right)<+\infty$ for each $h$, so that the first term on the right-hand side has a well-defined limit equal to $v_{w^{h}}\left(s^{t} ; p, a\right)$. It also implies that $v_{\tilde{w}}\left(s^{t} ; p, a\right)<+\infty$, which in turn yields that $v_{\bar{c}^{h}}\left(s^{t} ; p, a\right)<+\infty$, so that the first term on the left-hand side has a well-defined, finite limit. Finally, the fact that $v_{\tilde{w}}\left(s^{t} ; p, a\right)<+\infty$, together with the assumption that $\tilde{w}\left(s^{T}\right) \geq 0$ at all nodes, implies that the second term on the left-hand side converges to zero. This establishes (3.3).

Q.E.D.

The theorem is then proved as follows.

Proof of Theorem 3.3: Given Assumptions (A.1)-(A.2), the hypotheses of Lemma 3.8 necessarily hold for each $h \in H$, in any equilibrium. Summing (3.3) over $h$, and making use of equilibrium conditions $(1.3 \mathrm{~b})-(1.4 \mathrm{~b})$ we obtain

$$
\sum_{r=t+1}^{\infty} \sum_{\substack{s^{r} \mid s^{t} \\ s^{r} \in N^{h}}} \sum_{h \in H\left(s^{r}\right)} C^{h}\left(s^{r}\right) \geq a\left(s^{t}\right) v_{w}\left(s^{t} ; p, a\right)+a\left(s^{t}\right) q\left(s^{t}\right)^{\prime} z\left(s^{t}\right) .
$$


Note that because of the assumption that $v_{w}\left(s^{t} ; p, a\right)<+\infty$, the infinite sum on the left-hand side must also be well-defined and finite. Then, from equilibrium conditions (1.3a)-(1.4a) it follows that

$$
\sum_{r=t+1}^{\infty} \sum_{s^{r} \mid s^{\prime}} a\left(s^{r}\right) p\left(s^{r}\right)^{\prime} d\left(s^{r}\right) z\left(s^{r}-1\right) \geq a\left(s^{t}\right) q\left(s^{t}\right)^{\prime} z\left(s^{t}\right)
$$

which in turn implies

$$
\sum_{r=t+1}^{\infty} \sum_{s^{r} \mid s^{t}} a\left(s^{r}\right) p\left(s^{r}\right)^{\prime} x\left(s^{r} \mid s^{t}\right) z\left(s^{t}\right) \geq a\left(s^{t}\right) q\left(s^{t}\right)^{\prime} z\left(s^{t}\right) .
$$

On the other hand, Proposition 2.1 shows that the left-hand side of this inequality cannot exceed the right. Hence the weak inequality must actually hold as an equality, which implies that $\sigma\left(s^{t}\right)^{\prime} z\left(s^{t}\right)=0$. Thus we can now conclude, as in proof of Theorem 3.1, that the fundamental value must equal the market price in the case of any security in positive net supply or of finite maturity, for each $s^{T} \mid s^{t}$.

Q.E.D.

\section{REFERENCES}

Abel, A. B., N. G. Mankiw, L. H. Summers, and R. J. Zeckhauser (1989): “Assessing Dynamic Efficiency: Theory and Evidence," Review of Economic Studies, 56, 1-20.

BARRo, R. J. (1974): “Are Government Bonds Net Wealth?” Journal of Political Economy, 81, $1095-1117$.

BEwley, T. (1980): “The Optimum Quantity of Money,” in Models of Monetary Economies, ed. by J. Kareken and N. Wallace. Minneapolis: Federal Reserve Bank.

Blanchard, O. J. (1979): "Speculative Bubbles, Crashes, and Rational Expectations," Economic Letters, 3, 387-389.

Blanchard, O. J., AND S. Fischer (1989): Lectures on Macroeconomics. Cambridge, Mass.: M.I.T. Press.

Blanchard, O. J., AND P. Weil (1992): "Dynamic Efficiency, the Riskless Rate, and Debt Ponzi Games under Uncertainty," NBER Working Paper No. 3992.

BROCK, W. A. (1979): "An Integration of Stochastic Growth Theory and the Theory of Finance, Part I: The Growth Model," in General Equilibrium, Growth and Trade, ed. by J. Green and J. Scheinkman. New York: Academic Press.

- (1982): "Asset Prices in a Production Economy," in The Economics of Information and Uncertainty, ed. by J. McCall. Chicago: University of Chicago Press.

(1990): "Overlapping Generations Models with Money and Transactions Costs," in Handbook of Monetary Economics, Volume I, ed. by B. Friedman and F. Hahn. Amsterdam: North-Holland.

Broze, L., AND A. Szafarz (1991): The Econometric Analysis of Non-Uniqueness in Rational Expectations Models. Amsterdam: North-Holland.

Diba, B. T., AND H. I. Grossman (1988): "The Theory of Rational Bubbles in Stock Prices," Economic Journal, 98, 746-754.

DuffIE, D. (1988): Security Markets: Stochastic Models. Boston: Academic Press.

Froot, K. A., AND M. ObstFeld (1991): "Intrinsic Bubbles: The Case of Stock Prices," American Economic Review, 81, 1189-1214.

GALE, D. (1960): The Theory of Linear Economic Models. New York: McGraw-Hill.

(1973): "Pure Exchange Equilibrium of Dynamic Economic Models," Joumal of Economic Theory, 6, 12-36.

Gilles, C., AND S. F. LeRoy (1992): "Bubbles and Charges," International Economic Review, 33, 323-339.

(1993): "Stochastic Bubbles in Markov Economies," Finance and Economics Discussion Series No. 92-23, Federal Reserve Board of Governors. 
Hernandez, A., AND M. S. SANTos (1994): "Competitive Equilibria for Infinite-Horizon Economies with Incomplete Markets,” Mimeo, Centro de Investigación Económica, ITAM, México.

KAREKEN, J. H., AND N. WALLACE (1981): "On the Indeterminacy of Equilibrium Exchange Rates," Quarterly Journal of Economics, 96, 207-222.

KeHoe, T. J., D. K. Levine, ANd M. Woodford (1992): "The Optimum Quantity of Money Revisited," in Economic Analysis of Markets and Games, ed. by P. Dasgupta, D. Gale, O. Hart, and E. Maskin. Cambridge, Mass.: M.I.T. Press.

Kocherlakota, N. R. (1992): "Bubbles and Constraints on Debt Accumulation," Journal of Economic Theory, 57, 245-256.

KREPS, D. M. (1981): "Arbitrage and Equilibrium in Economies with Infinitely Many Commodities," Journal of Mathematical Economics, 8, 15-35.

LEvine, D. K., AND W. R. ZAME (1994): "Debt Constraints and Equilibrium in Infinite Horizon Economies with Incomplete Markets," Mimeo, U.C.L.A.; forthcoming in Journal of Mathematical Economics.

MAGILl, M., AND M. QuinziI (1994): "Infinite Horizon Incomplete Markets," Econometrica, 62, 853-880.

SAmuelson, P. A. (1958): "An Exact Consumption-Loan Model of Interest with or without the Social Contrivance of Money," Journal of Political Economy, 66, 467-482.

SANTos, M. S., AND M. Woodford (1993): "Rational Asset Pricing Bubbles," Discussion Paper No. 9304, Centro de Investigación Económica, ITAM, México. México.

SARgent, T. J. (1987): Dynamic Macroeconomic Theory. Cambridge, Mass.: Harvard University Press.

Schachermayer, W. (1994): "Martingale Measures for Discrete-Time Processes with Infinite Horizon," Mathematical Finance, 4, 25-55.

Scheinkman, J. A. (1977): "Notes on Asset Pricing," Mimeo, Univ. of Chicago.

(1988): "Dynamic General Equilibrium Models-Two Examples," in Mathematical Economics, ed. by A. Ambrosetti, F. Gori, and R. Lucchetti. New York: Springer-Verlag.

STiglitz, J. E. (1990): "Symposium on Bubbles," Journal of Economic Perspectives, 4, 13-18.

TiRole, J. (1982): "On the Possibility of Speculation under Rational Expectations," Econometrica, $50,1163-1182$.

(1985): "Asset Bubbles and Overlapping Generations," Econometrica, 53, 1499-1528.

WiLson, C. A. (1981): "Equilibrium in Dynamic Models with an Infinity of Agents," Journal of Economic Theory, 24, 95-111.

Woodford, M. (1994): "Monetary Policy and Price Level Determinacy in a Cash-in-Advance Economy," Economic Theory, 4, 345-380. 